\title{
The Economic Origins of the Evil Eye Belief*
}

\author{
Boris Gershman ${ }^{\dagger}$ \\ American University
}

June 2014

\begin{abstract}
The evil eye belief is a widespread superstition according to which people can cause harm by a mere envious glance at coveted objects or their owners. This paper argues that such belief originated and persisted as a useful heuristic under conditions in which envy was likely to trigger destructive behavior and the avoidance of other people's envy, effectively prescribed by the evil eye belief, was a proper response to that threat. We hypothesize that in weakly institutionalized societies wealth differentiation and vulnerability of productive assets were the key factors enabling envy-induced destructive behavior and contributing to the emergence and spread of the evil eye belief as a cultural defense mechanism. Evidence from small-scale preindustrial societies shows that there is indeed a robust positive association between the incidence of the belief and measures of wealth inequality, controlling for potential confounding factors such as patterns of spatial and cross-cultural diffusion and various dimensions of early economic development. Furthermore, the evil eye belief is more prevalent in agro-pastoral societies that tend to sustain higher levels of inequality and where vulnerable material wealth plays a dominant role in the subsistence economy.
\end{abstract}

Keywords: Culture, Envy, Evil eye belief, Inequality, Institutions, Superstition

JEL Classification Numbers: D31, D74, N30, O10, Z10, Z13

\footnotetext{
${ }^{*}$ Quamrul Ashraf, Pedro Dal Bó, James Fenske, Peter Leeson, Ross Levine, Glenn Loury, Stelios Michalopoulos, Jean-Philippe Platteau, and Louis Putterman provided valuable comments. I am especially grateful to Oded Galor, Peter Howitt, and David Weil for their advice. I also thank seminar and conference participants at Brown University, Williams College, the Fourth Workshop on Growth, History, and Development at the University of Southern Denmark, and the 2013 ASREC conference in Arlington.

${ }^{\dagger}$ Department of Economics, American University, 4400 Massachusetts Avenue NW, Washington, DC 20016-8029 (e-mail: boris.gershman@american.edu).
} 


\section{Introduction}

Over the recent years culture has been argued to be one of the key determinants of economic outcomes. ${ }^{1}$ Although early empirical research treated culture as an explanatory variable, increasing effort is being devoted to understanding how economic and environmental constraints, interacting with institutions and history, shaped certain cultural characteristics. ${ }^{2}$ This paper adds to the literature by investigating the origins of a particular cultural phenomenon known as the evil eye belief.

The evil eye belief is a widespread superstition according to which people can cause harm by a mere envious glance at coveted objects or their owners. In other words, it is a belief in the supernatural destructive force of envy projected through the eyes of the envier. Deeply ingrained in certain societies and transmitted through centuries, the evil eye belief is still actively present around the world. According to a 2009 survey conducted by the Pew Forum on Religion and Public Life, 16\% of Americans believe in the "evil eye, or that certain people can cast curses or spells that cause harm." 3 So do over $42 \%$ of respondents in a 2008-2009 survey conducted in Sub-Saharan Africa, with a substantial variation across nineteen participating countries. The latest study, carried out in 2011-2012 among Muslim populations of 24 countries, reveals that the belief is especially widespread in the Middle East and North Africa, with prevalence rates as high as $90 \%$ in Tunisia. ${ }^{4}$

As documented in the next section, the fear of the "evil eye" can have real adverse effects on the economic activity by hampering incentives to invest and accumulate wealth and leading to other types of unproductive behavior such as concealment of assets. Thus, it is important to understand the origins of the belief and the socioeconomic conditions that may contribute to its persistence.

\footnotetext{
${ }^{1}$ See various chapters in Platteau and Peccoud (2010) and Benhabib et al. (2011) for an overview.

${ }^{2}$ Alesina et al. (2013) link contemporary attitudes to female labor force participation and gender inequality to the historical use of plough in agriculture; Nunn and Wantchekon (2011) show that contemporary variation in trust levels across African ethnicities is associated with the historical intensity of slave trade; Durante (2010) traces the origins of social trust in European regions to climatic variability; Michalopoulos et al. (2012) relate the adoption of Islam to inequality in agricultural endowments. The role of basic natural environment in shaping culture has been explored extensively in anthropological research, see Harris (1977) for one of the classic contributions.

${ }^{3}$ The broad interpretation of the evil eye belief used in the survey does not allow to clearly distinguish it from beliefs in witchcraft and sorcery. Hence, these motivating data should be treated with caution. Further details on all cited surveys are available at http://pewforum.org.

${ }^{4}$ In an independent survey by Gallup Pakistan in 2010, 57\% of local respondents claimed to believe in the evil eye. Furthermore, $43 \%$ of them pointed out envy as the major force behind doing magic on someone, see http://www.gallup.com.pk for a summary of results.
} 
In search for the origins of the evil eye belief this paper employs the well-known approach to culture as a set of useful heuristics, or rules of thumb, that have evolved to facilitate decision making in a complex and uncertain environment. ${ }^{5}$ Specifically, we argue that the evil eye belief emerged and spread through cross-cultural contact as a useful rule of thumb prescribing envy-avoidance behavior that limits exposure to other people's harmful envy-motivated actions. Using a simple framework of production in the presence of envy we derive the conditions under which envy-avoidance is the rational response to the threat of destructive envy. These intuitive conditions include high wealth inequality, ease and effectiveness of envious "retaliation," and the strength of invidious comparisons. In the real world of boundedly rational people acting under uncertainty and costly information acquisition, the evil eye belief acts as a useful guide to envy-avoidance behavior in an environment that enables destructive envy. In the context of simple traditional societies, in which the belief was born thousands of years ago, wealth inequality, along with vulnerability and visibility of main productive assets, are the key features of such an environment.

We explore these predictions using the Standard Cross-Cultural Sample (SCCS), a dataset on 186 well-described preindustrial societies around the world. The data show that the incidence of the evil eye belief across these societies is indeed positively and significantly associated with measures of wealth inequality. This finding is robust to the inclusion of potential confounding factors such as spatial and cross-cultural diffusion, various dimensions of economic development, exposure to "classical" religion (Christianity, Islam, Buddhism, and Hinduism), and continental fixed effects. As expected, the pattern is stronger in societies with weaker institutions.

To provide further evidence in favor of the main hypothesis, we explore the relationship between the prevalence of the evil eye belief and the subsistence mode of production. The belief turns out to be more widespread in agricultural and pastoral societies which rely more on visible and vulnerable material wealth and sustain higher levels of inequality compared to foragers and horticulturalists (Borgerhoff Mulder et al., 2009).

Altogether, the empirical analysis is consistent with the view of the evil eye belief as a useful cultural response in an environment conducive to destructive manifestations of envy.

The rest of the paper is organized as follows. Next section examines the relationship between the evil eye belief and the fear of envy in light of ethnographic case studies from

\footnotetext{
${ }^{5}$ This approach has been advanced by anthropologists (Richerson and Boyd, 2005) and psychologists (Gigerenzer, 2008) and recently used by economists to explain the origins and persistence of culture, see Nunn (2012) for an overview. The idea about functional significance of superstitions and magical practices goes back to the pioneering writings of Bronisław Malinowski based on his fieldwork among the Trobriand islanders.
} 
around the world. Section 3 provides a conceptual framework for understanding the emergence and persistence of the belief. Section 4 conducts the empirical analysis. Section 5 concludes. Appendices contain a model of the rational fear of envy, detailed description of the data, and additional robustness checks.

\section{Evil eye belief as the fear of envy}

An analysis of the anthropological literature on the evil eye belief in various societies suggests that its common root is the fear of other people's envy. Envious gaze is believed to cause misfortunes manifested, among other things, in the damage to property (such as farm animals or shelter), production outcomes (such as crops), and health of the subject of envy. Numerous ethnographic studies reveal the following key regularities: 1) the evil eye belief reflects the fear of destructive envy which arises from inequality of economic outcomes; 2) the fear of the evil eye affects real economic decisions by discouraging effort, wealth accumulation, and upward mobility and encouraging unproductive practices such as concealment of wealth. The fear of envious glances is consistent with the notion that people perceive their own relative standing through observation of other people's material wealth which may trigger envious feelings. ${ }^{6}$

Anecdotal evidence on the adverse effects of the evil eye belief comes from across the globe. In Naçaawy, an Egyptian village, "the harmful effects of the envious glance are accepted as an article of faith" (Ghosh, 1983). Livestock, the main object of envy, and the main measure of wealth in the community, is kept in the recesses of the house to avoid the evil eye. Similarly, to avoid the envy of neighbors, villagers of a Teneek community in Mexico "weave the agave fibers in the darkness of their houses" (de Vidas, 2007). The fear of envy also makes them reject lucrative jobs and leave some ripe oranges on the trees to rot. In Tzintzuntzan, also in Mexico, villagers refuse to install glass windows in their houses fearing to attract envious looks (Foster, 1972). In Caixa de Água, Brazil, "envy dries crops, slays cattle, fells trees, pollutes food and water, causes houses to collapse, and can even kill small children" (Ansell, 2009). The fear of olho grande (the Brazilian name for the evil eye) makes the relatively rich peasants conceal or degrade the worth of their wealth. Back in the Old World, an Indian villager refuses to use a new fertilizer for the fear

\footnotetext{
${ }^{6}$ In many languages the expressions for "evil eye," "to see," and "envy" are closely related. In Arabic, for example, the "evil eye" is ayn al-hasu d literally meaning "the eye of envy." The Latin word invidia from which the English "envy" stems, derives from videre, "to see." Similarly, the Russian word for "envy," zavist', derives from the root of the verb videt', "to see."
} 
of nazar lagna (the Urdu name for the evil eye) in case the innovation delivers an especially good harvest (Schoeck, 1969). Similar fears and behaviors were also documented among the Bedouin tribes of Negev desert (Abu-Rabia, 2005), Galician villagers in Spain (LisónTolosana, 1973), and in Slovak-American communities of Western Pennsylvania (Stein, 1974). This body of ethnographic evidence highlights how the evil eye belief essentially enforces envy-avoidance behavior in different forms.

Most anthropological studies of the evil eye belief emphasize its deep connection to the underlying socioeconomic relations in a community. For instance, Schoeck (1981) classifies the evil eye belief as a "realistic fear" which "reveals man's deep knowledge that, no matter what our station in life, what our fortune or assets, there will always be someone who is less favored by life. And he is a potential enemy." Reminick (1974) in his study of the evil eye belief among the Amhara of Ethiopia suggests that there is a "social context" behind the belief and associated symbolic behaviors. Spooner (1970) considers it to be "an institutionalized psychological idiom for the personalization, or simply the personification of misfortune, in particular insofar as misfortune, or fear of it, may relate to the fear of outsiders and their envy." Wolf (1955) and Foster (1972) view the evil eye belief, along with witchcraft, sorcery, and gossip, as part of "institutionalized envy" which is a set of cultural indicators of the existence of envy in a community. Roberts (1976) looks at the evil eye belief through the lens of "conflict enculturation" theory according to which conflicts that are pervasive in society become part of expressive culture.

This paper offers a complementary theory based on the view of cultural norms as useful heuristics guiding behavior in an uncertain environment. Our approach also addresses a commonly raised objection to the envy basis of the evil eye belief, which is that, while envy is a universal phenomenon, the evil eye belief is not. As the framework of the following section demonstrates, existence of envy per se does not imply the optimality of envyavoidance behavior: destructive envy and the fear of it are only activated once wealth inequality surpasses a certain "tolerance threshold" that depends, in particular, on the visibility and vulnerability of productive assets, as well as institutional infrastructure.

\section{Conceptual framework}

Since the evil eye belief is rooted in the fear of envy, in order to trace its origins one has to characterize the environment in which envy-avoidance behavior, prescribed by the evil eye belief, is a proper response to the danger of envy-motivated aggression. Generally speaking, envy can be constructive and destructive, that is, people can satisfy it by either 
catching up with others or bringing them down. As formally demonstrated in Gershman (2014a), these two sides of envy lead to qualitatively different equilibria depending on the underlying economic and institutional environment.

A simple game-theoretic model sketched in appendix A helps to pin down the conditions that enable destructive envy and make envy-avoidance behavior optimal in a perfect fullinformation world. In this model, two individuals who have unequal initial endowments of wealth engage in a productive activity. Unequal production outcomes cause envy on part of the relatively poor individual who can then exert costly effort to assuage his feelings by harming the other individual. The game gives rise to two types of equilibria. In the "no fear" equilibrium, both individuals work peacefully and the resulting inequality of outcomes is not high enough to trigger envy-motivated destructive behavior. In the alternative "fear of envy" equilibrium, the wealthier individual anticipates envy-motivated retaliation and limits his productive effort in order to avoid it. Thus, in this case envyavoidance behavior in the form of underproduction is the optimal response to the prospect of envious retaliation.

The conditions under which the fear of envy equilibrium emerges are intuitive: high inequality, ease or effectiveness of envy-motivated retaliation, and the degree of enviousness itself. In the empirical analysis of the following section, we use measures of inequality to explain the variation in the prevalence of the evil eye belief in small-scale societies around the world. In addition, we explore the connection between the prevalence of the evil eye belief and subsistence production mode. As detailed in section 4.3, agro-pastoralists rely heavily on material wealth, such as tools, animals, and farm land, for subsistence, while for other production modes non-material wealth such as health, strength, and skills is more important. On the one hand, the reliance on material wealth tends to sustain higher inequality across generations (Borgerhoff Mulder et al., 2009). On the other hand, material wealth is both more visible and easily destructible which raises, respectively, the intensity of social comparisons and the effectiveness of envious retaliation. All of these factors enable destructive envy thus making envy-avoidance behavior appropriate. Hence, we expect to see higher incidence of the evil eye belief in agro-pastoral societies.

Although the model of appendix A does not formalize the emergence of the evil eye superstition, it highlights the characteristics that would make it a useful heuristic device in the real world. As established by social scientists, individuals often recur to "fast and frugal" heuristics for "guessing the right thing to do in a complex and variable environment" (Richerson and Boyd, 2005, p. 119). Indeed, if information is imperfect and learning through experimentation is costly, simple norms approximating rational behavior may 
be adaptive and become encoded in culture (Nunn, 2012). In the context of the above framework, there are several dimensions that may complicate fully rational behavior in the real imperfect-information world. For example, individuals may not know each other's cost functions and preferences making it difficult to calculate the exact optimal response.

In his work on traditional societies Diamond (2012, ch. 8) points out that behavioral rules that minimize risks in a dangerous environment are often worth following even if they seem overcautious. Under conditions in which envy leads to conflict, erring on the side of caution, that is, underinvesting, may be preferable to running a risk of inciting envy-motivated aggression. Hence, a belief that a mere envious glance can cause damage becomes a winning strategy that, despite being too conservative in certain cases, allows to avoid severe conflict and major risk posed by the envy of others. ${ }^{7}$

Scheibe and Sarbin (1965) argued that under conditions of uncertainty "extralogical propositions, such as superstitions, are necessary guides to action." Indeed, the evil eye belief is based on the fear of a supernatural destructive force of envy rather than rational fear of envious retaliation by neighbors. One possible explanation is that the latter is more likely to trigger accusations and costly open hostility. Hence, the idea that a neighbor is a potential enemy intentionally destroying other people's possessions is replaced by a belief in the supernatural destructive power of an envious glance that cannot be controlled. As a result, given the imperfect information about the real cause of a misfortune, the evil eye belief provides both an explanation and a rough guide to preemptive action (envyavoidance) without escalating open conflict and direct accusations. ${ }^{8}$

The approach to the evil eye belief offered in this paper is related to Peter Leeson's research on the "law and economics of superstition." He argues that, in the absence of modern legal infrastructure and secure property rights, certain superstitions can fill in that institutional gap, even if imperfectly, and thus are socially useful. Examples include medieval judicial ordeals in Europe (Leeson, 2012), trial by poison ingestion in Liberia (Leeson and Coyne, 2012), and even the practice of human sacrifice in some societies (Leeson, 2014). The latter paper argues that human sacrifice is in fact a primitive technology of property rights protection. Specifically, "conspicuous destruction" of wealth by way of exchang-

\footnotetext{
${ }^{7}$ Foster and Kokko (2009) construct a simple evolutionary model in which natural selection may favor superstitious strategies that lump non-causal associations with causal ones. Beck and Forstmeier (2005) argue that, although superstitious behavior itself may not be adaptive, it is an inevitable by-product of an adaptive learning strategy.

${ }^{8}$ In contrast, witchcraft beliefs view misfortunes as malevolent acts (driven by envy, among other things) and thus are more hostile by nature. Open accusations of witchcraft often lead to conflict entailing severe sanctions and eroding social capital (Gershman, 2014b).
} 
ing valuable property for humans that are subsequently sacrificed makes the community poorer. This reduces the expected payoff from plundering and protects the community from external predation. Envy-avoidance behavior such as underinvestment and concealment of wealth, prescribed by the evil eye belief, is a less cruel and spectacular way to achieve a similar goal within community, that is, reduce the likelihood of (envy-motivated) destruction. As in Leeson's work, one of the key ingredients to the story is the absence of effective government and formal protection of property rights which makes informal substitutes for such protection useful. In the sample used in the empirical analysis of the next section most societies are traditional communities lacking modern institutions. Yet we attempt to explore the interaction between inequality and rough measures of basic institutions to see whether in weakly institutionalized environments the connection between inequality and the incidence of the evil eye belief is stronger. ${ }^{9}$

Culture and superstitions in particular tend to persist over time, especially if the socioeconomic environment makes them socially valuable. ${ }^{10}$ An additional mechanism of persistence is provided by Fudenberg and Levine (2006) who take a formal game-theoretic approach to superstitions using the concept of self-confirming equilibrium. In particular, they call the objectively false beliefs about the off-equilibrium actions "superstitions" and show that such beliefs can persist for a long time if they prevent actions that could provide new information to disconfirm prior beliefs (see also Fudenberg and Levine, 2009). From the standpoint of the fear of envy theory and its connection to the evil eye belief, if individuals believe that an envious glance can cause real harm, they underinvest thereby avoiding destructive envy and generating no data to disconfirm their prior belief. Furthermore, if the source of destruction is not perfectly observable, the evil eye belief is more likely to persist in an environment enabling destructive envy. If an individual decides to experiment and invest full effort, he is more likely to suffer from envious retaliation in such environment. Hence, believing in the evil eye becomes an adaptive strategy that allows believers to avoid envy-motivated aggression. The concept of self-confirmation also shows that cultural rules and customs may persist over time even when they are no longer useful.

\footnotetext{
${ }^{9}$ The interaction between institutions and culture is also explored in the work by Grosjean (2014) on the culture of violence in the U.S. She argues that such culture was brought by the Scottish and Irish immigrants but persisted only in the U.S. South, where low institutional quality made the "culture of honor" an adaptive trait.

${ }^{10}$ For excellent literature reviews on cultural persistence see Bisin and Verdier (2011) and Nunn (2012). For an anthropologist's perspective see Chibnik (1981).
} 


\section{Evidence}

\subsection{Data}

To empirically investigate the economic origins of the evil eye belief we resort to the Standard Cross-Cultural Sample, a "representative sample of the world's known and well described cultures, 186 in number, each "pinpointed" to the smallest identifiable subgroup of the society in question at a specific point in time" (Murdock and White, 1969). The SCCS is a subsample from a broader dataset, the Ethnographic Atlas (EA), which includes 1167 societies (Murdock, 1967). One of the motivations for creating the SCCS was to construct a sample spanning a wide range of diverse societies all around the world documented at a time of maximum cultural independence, in order to alleviate the problem of spatial correlation crucial for sound statistical analysis. The SCCS covers preindustrial societies, from foragers like the Hadza people of the central Rift Valley in Africa to technologically advanced agriculturalists like the Basques of the Iberian Peninsula (see figure 1 for exact geographic locations). ${ }^{11}$

The original publication by Murdock and White was substantially expanded in the following years accumulating a wealth of coded data (around 2,000 variables) on subsistence economy and cultural characteristics of the SCCS societies. Heavily used by anthropologists, the SCCS and the EA data are increasingly employed by economists, recent examples being Baker (2008) on the transition to agriculture, Fenske (2013; 2014) and Michalopoulos and Papaioannou (2013) on pre-colonial African institutions, Alesina et al. (2013) on the origins of gender roles, and Giuliano and Nunn (2013) on the transmission of democracy.

The dependent variable of interest is the presence of the evil eye belief as coded for the SCCS by Roberts (1976) according to the following ordinal scale: incontrovertibly absent (1), almost certainly absent (2), probably absent (3), possibly absent (4), possibly present (5), probably present (6), almost certainly present (7), incontrovertibly present (8). ${ }^{12}$ Roberts also suggested a binary measure by separating the first four categories (absent) from the last four (present). According to this last measure, the evil eye belief was present in $36 \%$ of societies (67 in total) at the date of pinpointing. The geographical distribution of the belief is represented in figure 1. It is ubiquitous in the Circum-Mediterranean

\footnotetext{
${ }^{11}$ The mean pinpointing date is 1853 , although it moves closer to 1900 when ancient empires like the Romans and the Babylonians are dropped. The main results are based on the full sample of 186 societies, but they are robust to omitting the twelve cultures pinpointed before 1800, see section 4.4. The breakdown of the SCCS by pinpointing date is given in table C.1 of appendix C.

${ }^{12}$ The coding was done on the basis of published sources on each society.
} 


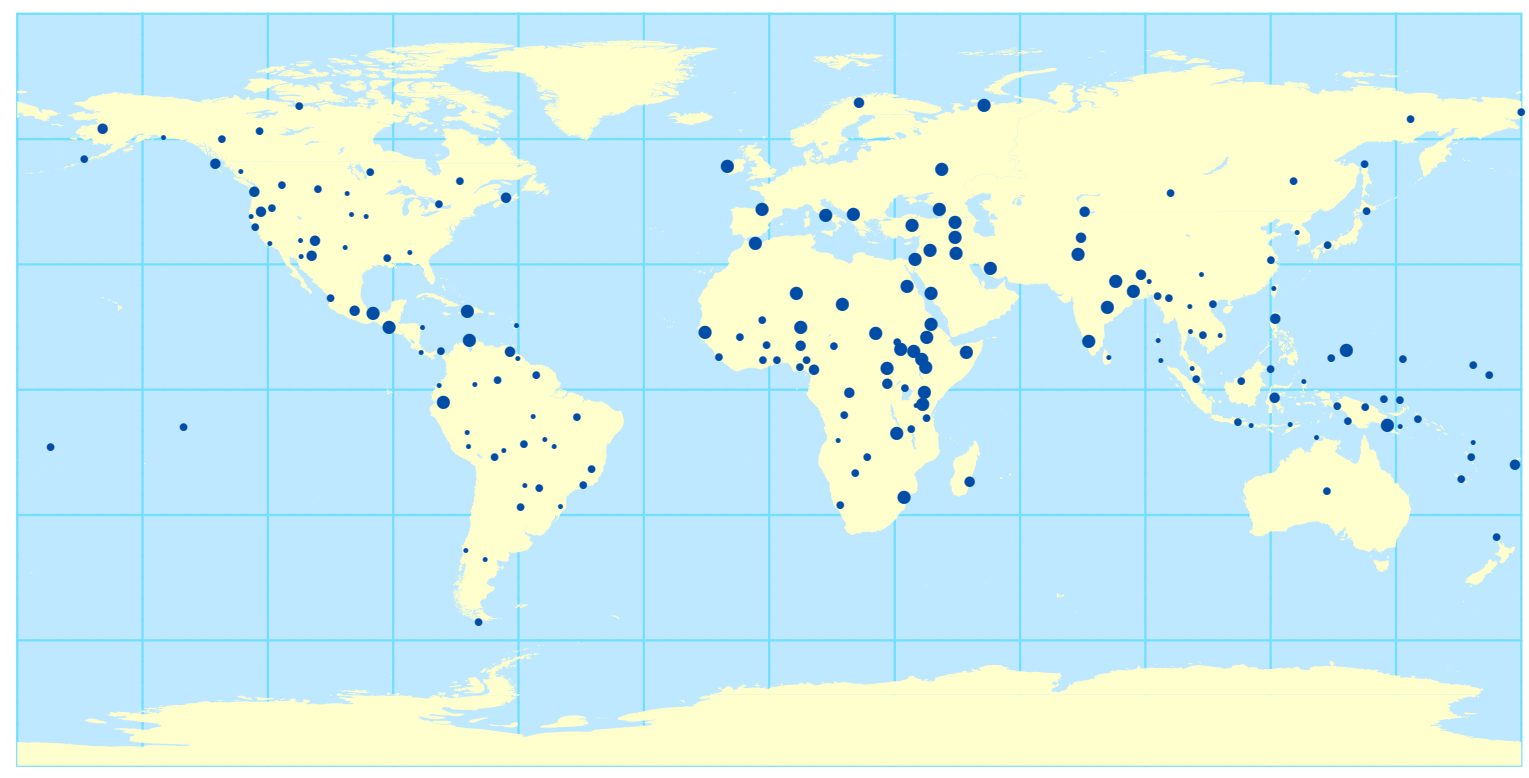

Figure 1: The evil eye belief across the SCCS societies.

Note. The circle size varies according to the evil eye scale: $1-2$ (smallest), 3-4, 5-6, and 7-8 (largest).

region broadly defined, actively present in South Asia and Central America, and much less prominent among the aboriginal populations of the rest of the globe.

In the following analysis we use two measures as proxies for wealth inequality. The first measure is the stratification dummy adapted from Murdock (1967). The original scale comprises the following categories: absence of significant wealth distinctions among freemen (1); wealth distinctions based on the possession and distribution of property, not crystallized into distinct social classes (2); elite stratification, in which an elite class has control over scarce resources, particularly land (3); dual stratification into a hereditary aristocracy and a lower class of ordinary commoners or freemen (4); complex stratification into social classes correlated in large measure with extensive differentiation of occupational statuses (5). Since this scale is not really ordinal, it is converted into egalitarian/stratified dummy, which equals 0 , if the society is of the first type, and 1, otherwise. ${ }^{13}$ Around $41 \%$ of the SCCS societies (76 in total) qualified as egalitarian at the date of pinpointing. Figure 2 shows the proportion of egalitarian and stratified societies in each of the eight evil eye belief categories. Clearly, there is a positive association between stratification and the prevalence of the evil eye belief.

We also construct a finer proxy for inequality by adjusting the previous dummy variable for the complexity of technological specialization. In the absence of perfect mobility, which

\footnotetext{
${ }^{13}$ Similar strategy was used by Gennaioli and Rainer (2007) and Michalopoulos and Papaioannou (2013).
} 


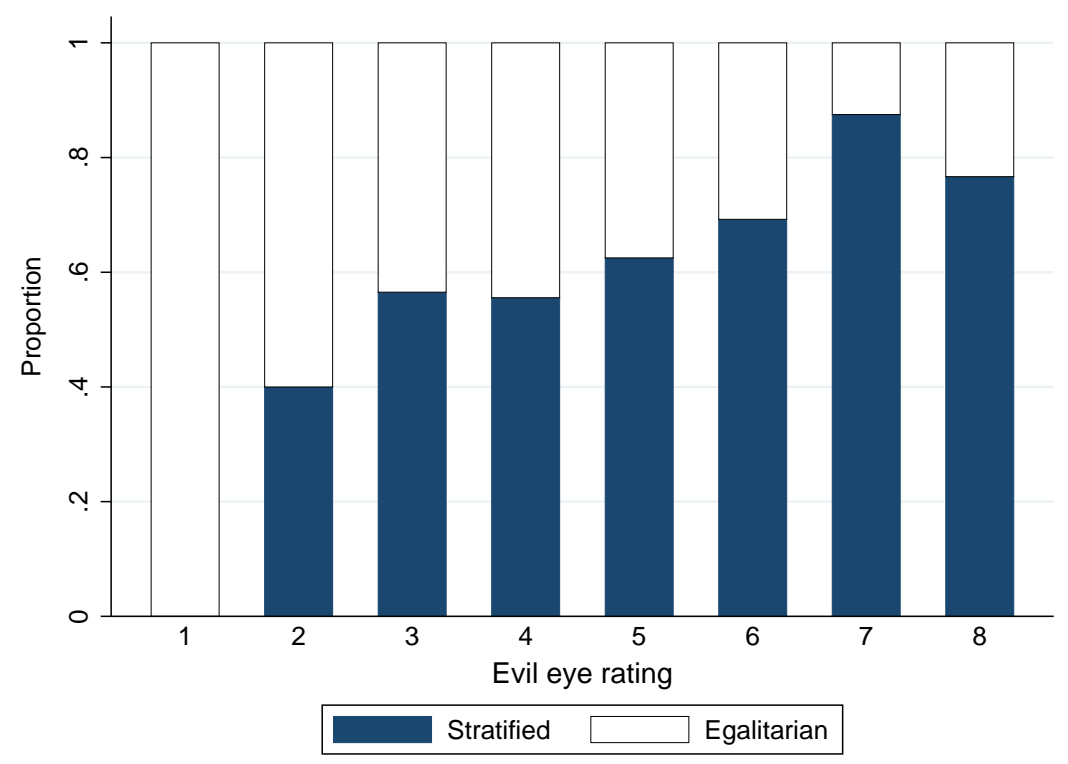

Figure 2: Stratification and the evil eye belief.

Note. The number of societies in each of the eight bins is $1,45,46,27,8,13,16$, and 30 , respectively.

is a plausible assumption for the SCCS societies, a complex occupational specialization is likely to generate economic inequality. ${ }^{14}$ The measure of technological specialization comes from Murdock and Provost (1973) and comprises the following categories: none (1); pottery only (2); loom weaving only (3); metalwork only (4); smiths, weavers, potters (5). We convert this variable into an ordinal measure of specialization: none (1), simple (2), complex (3). We then multiply the stratification indicator by this three-category scale to obtain the final measure of inequality based on technological specialization. By construction, the resulting variable is highly correlated with the stratification dummy, but gives more variation across stratified societies.

\subsection{Baseline results}

We use two baseline specifications. The first one has the full-scale measure of the evil eye belief on the left-hand side:

$$
\text { eye }_{i}=\alpha+\beta \text { inequality }_{i}+\mathbf{X}_{\mathbf{i}}^{\prime} \Gamma+\mathbf{D}_{\mathbf{i}}^{\prime} \Delta+\varepsilon_{i},
$$

\footnotetext{
${ }^{14}$ Henrich and Boyd (2008) provide a simple model showing how occupational specialization between groups can lead to inequality when people occupying different economic roles are partially culturally isolated. They also apply their model to interpret the observed coexistence of specialized occupational groups with different mean payoffs across occupations among Swat Pathans in Pakistan.
} 
where $i$ corresponds to an SCCS society, eye is the measure of the evil eye belief on the ordinal 1-8 scale, inequality is one of the two proxies for wealth inequality, $\mathbf{X}^{\prime}$ is a vector of control variables, $\mathbf{D}^{\prime}$ is a vector of continental dummies and $\varepsilon$ is the society-level idiosyncratic component. The coefficient of interest, $\beta$, relates inequality and the incidence of the evil eye belief after partialling out the effects of $\mathbf{X}$ and $\mathbf{D}$. According to the fear of envy theory, $\beta$ is expected to be positive. The model is estimated via OLS. ${ }^{15}$ The second specification is the binary choice model (probit) with the absent/present dummy on the left-hand side:

$$
\mathbf{P}\left\{\text { bieye }_{i}=1 \mid \text { inequality }_{i}, \mathbf{X}_{\mathbf{i}}^{\prime}, \mathbf{D}_{\mathbf{i}}^{\prime}\right\}=\Phi\left(\tilde{\alpha}+\tilde{\beta} \text { inequality }_{i}+\mathbf{X}_{\mathbf{i}}^{\prime} \tilde{\Gamma}+\mathbf{D}_{\mathbf{i}}^{\prime} \tilde{\Delta}\right),
$$

where bieye is the indicator of the presence of the evil eye belief and $\Phi$ is the CDF of standard normal distribution. This model is estimated via maximum likelihood (ML).

The set of control variables covers three main groups which are incorporated in the estimation one by one. ${ }^{16}$ The first group includes variables that capture possible spatial diffusion of the belief. Some ethnographers hypothesize that the evil eye belief originated in the Circum-Mediterranean area, presumably in Mesopotamia, where the first references to it were documented in cuneiform texts (Thomsen, 1992), and then spread throughout the region and beyond. This is corroborated by figure 1 which indicates active presence of the belief in that region. Early scholars claimed that societies all over the world might have had an indigenous evil eye belief. In their classical works Seligmann (1910) and Elworthy (1895) call it, respectively, the "superstition of all times and people" and "ancient and widespread superstition." Yet the data clearly reject the universality hypothesis, and the framework of section 3 provides a possible explanation for this. The middle ground in the debate is that the observed world distribution is a combination of indigenous and "acquired" beliefs. ${ }^{17}$

The working hypothesis of the following analysis is that, even if the evil eye belief is not indigenous in a given society, it was more likely to have been adopted as a result of cross-cultural contact if the recipient society is unequal, that is, if the belief is relevant given the underlying socioeconomic conditions.

To account for spatial diffusion from Mesopotamia we control for the (great circle) distance from each society in the Old World to ancient Babylon. For the New World, we

\footnotetext{
${ }^{15}$ Ordered probit results are qualitatively similar, see tables D.1 and D.2 in appendix D.

${ }^{16}$ Descriptive statistics and detailed description of all variables may be found in appendices B and C.

${ }^{17}$ In his work on Aztec folk medicine Ortiz de Montellano (1989) points out that, albeit the evil eye belief could have been brought to Mesoamerica by the Europeans, the presence of a similar local belief, ihiyotl, facilitated its adoption.
} 
control for the distance of each society to the location of Tenochtitlan, capital of the Aztec empire that historically could have been the first SCCS society to acquire the evil eye belief from Spaniards. Furthermore, distance to coastline may proxy for the ease of contact with other cultures and is included as a control variable. ${ }^{18}$ All distances are measured in thousands of kilometers. Apart from these distance controls, all specifications use continental fixed effects for Africa, Eurasia, Oceania, North America and South America (see table C.1 for the breakdown of the SCCS by continent). ${ }^{19}$

Tables 1 and 2 show the estimation results controlling for this first group of "spatial" controls. The coefficient estimates on two inequality measures are highly economically and statistically significant. According to the estimates in table 2, controlling for distances and continental dummies, a stratified society is, on average, 19 percentage points more likely to possess the evil eye belief. Similarly, taking the estimate from column (6) in table 1, a one-step-ahead move on the specialization scale increases the evil eye belief rating by an average of 0.35 , while a jump from egalitarian society (0) to the unequal one with complex specialization (3) would mean an increase by more than 1 unit.

The distance measures themselves are significant and substantial in magnitude, especially the distance to Babylon, the alleged place of origin of the belief in the Old World. Note, however, that these distances are likely to capture effects far beyond the spatial diffusion of the belief via cross-cultural interactions. The historical homelands of Babylonians and Aztecs were the cradles of the Neolithic Revolutions in the Old and the New World, respectively (Diamond and Bellwood, 2003). As discussed in more detail below, agricultural revolution and domestication of animals were important forces leading to economic complexity in general and wealth differentiation in particular. Hence, the included distances measure geographical proximity to ancient technological frontiers and may partially capture the effects that should be attributed to inequality rather than spatial diffusion.

Economic development. Social stratification is often viewed as one of the by-products of early economic development (see, e.g., Johnson and Earle, 1987). Ideally, one would want to isolate the role of wealth inequality and show that it is this particular dimension of development that is triggering the emergence or adoption of the evil eye belief. Thus, we control for a host of variables that were argued to be proximate correlates of early

\footnotetext{
${ }^{18}$ For Africa, it is also a good proxy for involvement in slave trade (Nunn and Wantchekon, 2011) through which the transmission of belief might have occurred.

${ }^{19}$ In section 4.4 we address the problem of cross-cultural diffusion in a more rigorous way by estimating spatial lag models. We also provide alternative estimates of standard errors that account for potential spatial autocorrelation. As it turns out, regular White's robust standard errors are the most conservative in the majority of cases and hence, are reported in all tables by default.
} 
Table 1: Evil eye and inequality: controlling for distances. OLS estimates

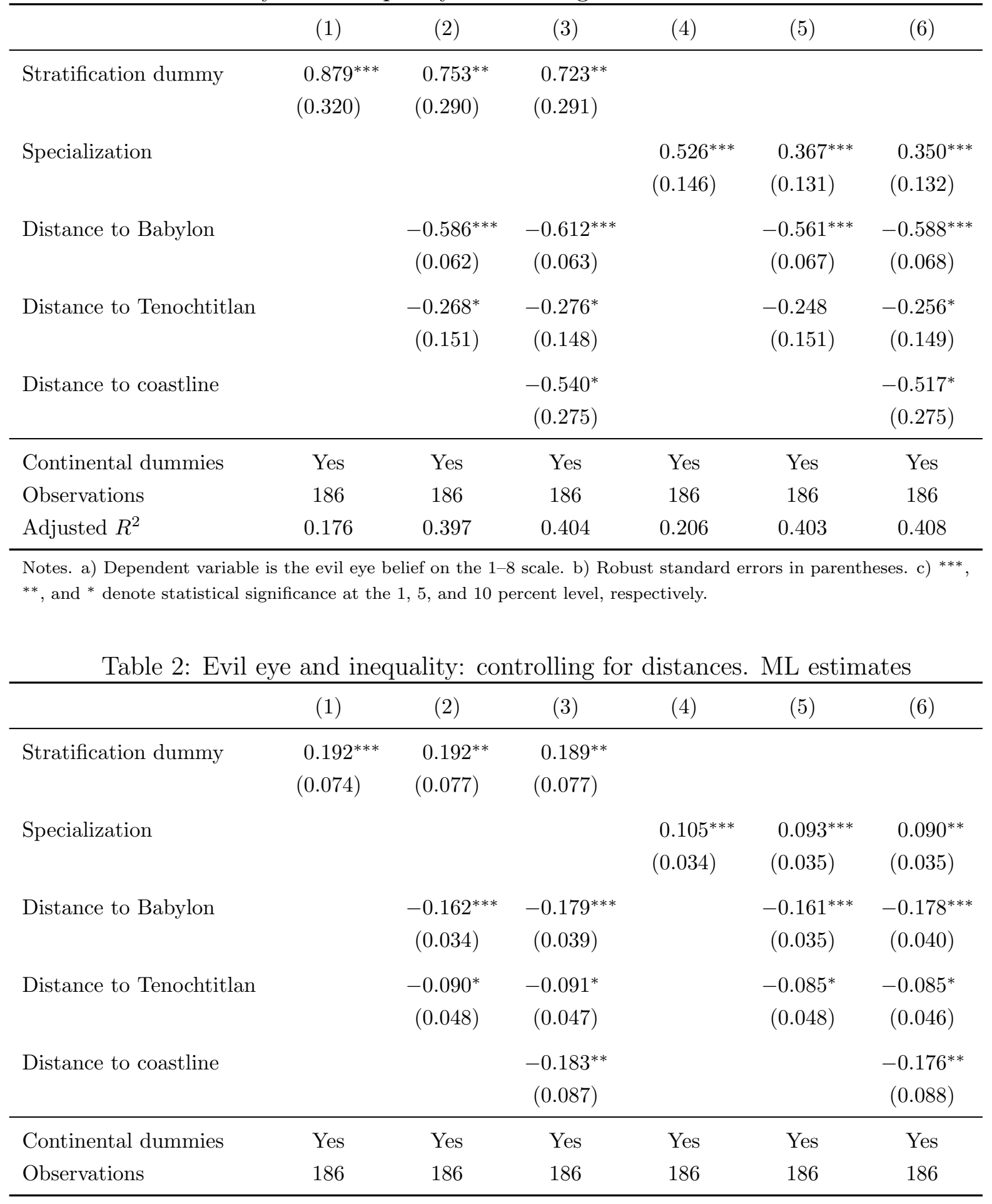

Notes. a) Dependent variable is the evil eye belief on the binary scale. b) Marginal effects displayed, robust standard errors in parentheses. c) ${ }^{* * *},{ }^{* *}$, and ${ }^{*}$ denote statistical significance at the 1,5 , and 10 percent level, respectively. 
development. Murdock and Provost (1973) coded various scales of cultural complexity for the SCCS. One of them is social stratification, the primary variable of interest, while other ordinal measures include urbanization level, population density, settlement pattern (from fully nomadic to permanent settlements), presence of money, and levels of hierarchy in the local community. ${ }^{20}$ Most of these variables are positively correlated with inequality and among themselves (see table C.3 in appendix C). Tables 3 and 4 show the effects of adding development controls to the baseline specification. The coefficient estimates on inequality remain statistically and economically significant, and their magnitude is relatively stable. Curiously, when either inequality measure is included, none of the other correlates of economic development is statistically significant (except for the presence of indigenous money in one specification).

Institutions. Institutions play an important role in our framework explaining the origins and persistence of the evil eye belief. As argued earlier, such a cultural rule of thumb is especially useful in a weakly institutionalized environment in which destructive envy is not contained via formal laws and individual envy-avoidance prescribed by the evil eye belief is a possible second-best solution. Consequently, we expect inequality to be more strongly associated with the prevalence of the evil eye belief in societies lacking formal institutions.

While all of the SCCS societies are weakly institutionalized by modern standards, there is still some variation in the available simple measures of institutional development. We use two such measures. The first one captures the presence of individual rights on movable property. The second measure is an ordinal index of jurisdictional hierarchy beyond the local community which is a proxy for the complexity of political organization or the presence of centralized government. The latter measure has been argued to capture the quality of pre-colonial institutions and is associated with contemporary economic development in Africa (Michalopoulos and Papaioannou, 2013).

Table 5 shows the estimation results when we include these two variables in the empirical model in addition to measures of inequality, as well as interacted with them. First, note that in columns (2) and (5) the coefficient estimates on property rights indicator have a positive sign, but are insignificant, while inequality measures remain statistically significant and of similar magnitude as before. ${ }^{21}$ These positive estimates may be interpreted as follows. On

\footnotetext{
${ }^{20}$ Ashraf and Galor (2011) have empirically demonstrated that population density is the relevant variable for measuring economic development in the preindustrial Malthusian world. See appendix B for detailed definitions of all control variables.

${ }^{21}$ Probit estimates are qualitatively the same and are omitted. When the sample is limited to only those societies that do have property rights ( $86 \%$ of the sample), the positive association between the incidence of the evil eye belief and inequality remains strong.
} 
Table 3: Evil eye and inequality: adding development controls. OLS estimates

\begin{tabular}{|c|c|c|c|c|c|c|}
\hline & (1) & $(2)$ & (3) & (4) & (5) & (6) \\
\hline Stratification dummy & $\begin{array}{c}0.704^{* *} \\
(0.304)\end{array}$ & $\begin{array}{c}0.744^{* *} \\
(0.301)\end{array}$ & $\begin{array}{c}0.708^{* *} \\
(0.291)\end{array}$ & & & \\
\hline Specialization & & & & $\begin{array}{c}0.362^{* *} \\
(0.145)\end{array}$ & $\begin{array}{l}0.407^{* * *} \\
(0.145)\end{array}$ & $\begin{array}{l}0.370^{* * *} \\
(0.141)\end{array}$ \\
\hline Population density & $\begin{array}{c}0.019 \\
(0.107)\end{array}$ & $\begin{array}{c}0.139 \\
(0.144)\end{array}$ & $\begin{array}{c}0.090 \\
(0.146)\end{array}$ & $\begin{array}{c}-0.022 \\
(0.112)\end{array}$ & $\begin{array}{c}0.120 \\
(0.143)\end{array}$ & $\begin{array}{c}0.086 \\
(0.145)\end{array}$ \\
\hline Urbanization & & $\begin{array}{r}-0.064 \\
(0.113)\end{array}$ & $\begin{array}{c}-0.064 \\
(0.112)\end{array}$ & & $\begin{array}{r}-0.107 \\
(0.113)\end{array}$ & $\begin{array}{c}-0.101 \\
(0.112)\end{array}$ \\
\hline Settlement pattern & & $\begin{array}{c}-0.123 \\
(0.122)\end{array}$ & $\begin{array}{r}-0.131 \\
(0.123)\end{array}$ & & $\begin{array}{r}-0.136 \\
(0.120)\end{array}$ & $\begin{array}{r}-0.140 \\
(0.123)\end{array}$ \\
\hline Money & & & $\begin{array}{c}0.186^{*} \\
(0.110)\end{array}$ & & & $\begin{array}{c}0.152 \\
(0.110)\end{array}$ \\
\hline Local hierarchy & & & $\begin{array}{r}-0.173 \\
(0.221)\end{array}$ & & & $\begin{array}{r}-0.149 \\
(0.224)\end{array}$ \\
\hline Continental dummies & Yes & Yes & Yes & Yes & Yes & Yes \\
\hline Distance controls & Yes & Yes & Yes & Yes & Yes & Yes \\
\hline Observations & 186 & 186 & 186 & 186 & 186 & 186 \\
\hline Adjusted $R^{2}$ & 0.400 & 0.399 & 0.403 & 0.405 & 0.406 & 0.407 \\
\hline
\end{tabular}

Notes. a) Dependent variable is the evil eye belief on the 1-8 scale. b) Robust standard errors in parentheses. c) $* * *$,

**, and ${ }^{*}$ denote statistical significance at the 1,5 , and 10 percent level, respectively.

Table 4: Evil eye and inequality: adding development controls. ML estimates

\begin{tabular}{lcccccc}
\hline & $(1)$ & $(2)$ & $(3)$ & $(4)$ & $(5)$ & $(6)$ \\
\hline Stratification dummy & $0.219^{* * *}$ & $0.236^{* * *}$ & $0.221^{* * *}$ & & & \\
& $(0.077)$ & $(0.078)$ & $(0.079)$ & & & \\
Specialization & & & & $0.114^{* * *}$ & $0.131^{* * *}$ & $0.120^{* * *}$ \\
& & & & $(0.038)$ & $(0.040)$ & $(0.040)$ \\
\hline Continental dummies & Yes & Yes & Yes & Yes & Yes & Yes \\
Distance controls & Yes & Yes & Yes & Yes & Yes & Yes \\
Observations & 186 & 186 & 186 & 186 & 186 & 186 \\
\hline
\end{tabular}

Notes. a) Dependent variable is the evil eye belief on the binary scale. b) Marginal effects displayed, robust standard errors in parentheses. c) ${ }^{* * *},{ }^{* *}$, and ${ }^{*}$ denote statistical significance at the 1,5 , and 10 percent level, respectively. d) Each specification includes the same set of development controls as the respective specification in table 3. None of those control variables is statistically significant at the 10 percent level. 
the one hand, the presence of individual property rights is contributing to the existence of substantial wealth inequality, as corroborated by the positive correlation between the respective variables (see table C.3 in appendix C). On the other hand, the recognition of individual property rights per se may enable social comparisons (Davidson, 2009), as opposed to the situation, in which property is common, and so, there is less reason for envy. As shown in panel (b) of table 5, similar pattern of results applies to the political centralization index.

Interestingly, the coefficient estimates on interaction terms are negative in all cases, although not precisely estimated. This is consistent with the idea that inequality is more likely to trigger destructive envy in a weakly institutionalized environment. Hence, the relationship between the prevalence of the evil eye belief and inequality is stronger in societies in which property rights are absent and there is less political centralization.

Classical religion. It is important to note how classical religion (Christianity, Islam, Buddhism, and Hinduism), a common object of research in recent literature on the economics of culture, fits into present analysis. The evil eye belief predates all major classical religions. Moreover, it was firmly incorporated into the main religious texts of Christianity, Islam, and Hinduism, as well as associated broader cultures. ${ }^{22}$

On the one hand, this implies mechanically that the diffusion of these classical religions throughout the world could have automatically contributed to the diffusion of the evil eye belief as their integral part. On the other hand, perhaps more importantly, there was a reason in the first place for incorporating this superstition in a collection of beliefs and behavioral rules dictated by religious teachings. This is perfectly consistent with the conceptual framework of the previous section: as long as destructive envy is a real threat and the evil eye belief represents a beneficial rule-of-thumb for envy-avoidance behavior, it becomes naturally integrated into a broad set of useful practices. This goes in line with the fact that envy features prominently as a major vice in both Judeo-Christian tradition (recall the Tenth Commandment and the seven deadly sins) and Islam (in which "hasad," destructive envy, is condemned as an evil and dangerous emotion). Not surprisingly, all societies in the SCCS, classified by Korotayev (2004) as "deeply" Islamic, Christian, or Hinduist, do possess the evil eye belief as part of their culture.

\footnotetext{
${ }^{22}$ See Elliott (1994) for biblical references, Gächter (1998) for the presence of the evil eye belief in Hinduism, and the Pew Forum report "The World's Muslims: Unity and Diversity" on Islam, available at http://www . pewforum.org/Muslim/the-worlds-muslims-unity-and-diversity . aspx.
} 
Table 5: Evil eye, inequality, and institutions. OLS estimates

\begin{tabular}{|c|c|c|c|c|c|c|}
\hline \multirow{3}{*}{ Stratification } & $(1)$ & $(2)$ & $(3)$ & $(4)$ & $(5)$ & (6) \\
\hline & \multicolumn{6}{|c|}{ (a) Property rights indicator ("rights") } \\
\hline & $\begin{array}{l}0.879^{* * *} \\
(0.311)\end{array}$ & $\begin{array}{l}0.842^{* * *} \\
(0.317)\end{array}$ & $\begin{array}{c}1.748^{* *} \\
(0.682)\end{array}$ & & & \\
\hline Specialization & & & & $\begin{array}{c}0.387^{* *} \\
(0.150)\end{array}$ & $\begin{array}{c}0.373^{* *} \\
(0.152)\end{array}$ & $\begin{array}{l}1.010^{* *} \\
(0.463)\end{array}$ \\
\hline Rights & & $\begin{array}{c}0.378 \\
(0.397)\end{array}$ & $\begin{array}{c}0.694 \\
(0.473)\end{array}$ & & $\begin{array}{c}0.421 \\
(0.405)\end{array}$ & $\begin{array}{c}0.754^{*} \\
(0.451)\end{array}$ \\
\hline Stratification $\times$ rights & & & $\begin{array}{r}-1.006 \\
(0.745)\end{array}$ & & & \\
\hline Specialization $\times$ rights & & & & & & $\begin{array}{r}-0.672 \\
(0.474)\end{array}$ \\
\hline Observations & 152 & 152 & 152 & 152 & 152 & 152 \\
\hline \multirow[t]{2}{*}{ Adjusted $R^{2}$} & 0.400 & 0.398 & 0.398 & 0.397 & 0.396 & 0.398 \\
\hline & \multicolumn{6}{|c|}{ (b) Index of political organization ("government") } \\
\hline Stratification & $\begin{array}{c}0.734^{* *} \\
(0.286)\end{array}$ & $\begin{array}{c}0.690^{* *} \\
(0.298)\end{array}$ & $\begin{array}{l}1.181^{* *} \\
(0.583)\end{array}$ & & & \\
\hline Specialization & & & & $\begin{array}{l}0.382^{* * *} \\
(0.139)\end{array}$ & $\begin{array}{c}0.372^{* *} \\
(0.151)\end{array}$ & $\begin{array}{l}0.683^{* * *} \\
(0.254)\end{array}$ \\
\hline Government & & $\begin{array}{c}0.088 \\
(0.158)\end{array}$ & $\begin{array}{c}0.345 \\
(0.288)\end{array}$ & & $\begin{array}{c}0.026 \\
(0.165)\end{array}$ & $\begin{array}{c}0.359 \\
(0.255)\end{array}$ \\
\hline Stratification $\times$ government & & & $\begin{array}{r}-0.300 \\
(0.294)\end{array}$ & & & \\
\hline Specialization $\times$ government & & & & & & $\begin{array}{r}-0.159 \\
(0.097)\end{array}$ \\
\hline Observations & 186 & 186 & 186 & 186 & 186 & 186 \\
\hline Adjusted $R^{2}$ & 0.405 & 0.403 & 0.402 & 0.409 & 0.406 & 0.410 \\
\hline Continental dummies & Yes & Yes & Yes & Yes & Yes & Yes \\
\hline Distance controls & Yes & Yes & Yes & Yes & Yes & Yes \\
\hline Development controls & Yes & Yes & Yes & Yes & Yes & Yes \\
\hline
\end{tabular}


To the extent that both the evil eye belief and some religious norms are driven by conflict related to inequality, it is hard to separate the two in the empirical analysis. ${ }^{23}$ It is still instructive to look at the earlier baseline specifications while controlling for the presence of classical religion. First, based on earlier considerations one should expect classical religion to be positively related to the evil eye belief. Second, within a group of societies that were not heavily influenced by classical religions, more unequal ones should be more likely to have the evil eye belief.

These predictions are corroborated by estimates in table 6. Models in columns (1) and (2) include the detailed classification of the SCCS societies into seven categories: traditional religion (116 observations), deep islamization (19), superficial islamization (7), deep christianization (6), superficial christianization (24), Buddhism (10), and Hinduism (4). Compared to the baseline results, the coefficient estimates on inequality proxies are somewhat smaller while remaining statistically significant at the 5 percent level. Furthermore, as expected, being profoundly affected by one of the three classical religions (Islam, Christianity, and Hinduism) is strongly positively correlated with the prevalence of the evil eye belief. Buddhist influence seems to operate in the opposite way, although the coefficient estimate is only weakly significant. Superficial exposure to either Islam or Christianity does not yield statistically significant differences compared to traditional religion (although the associated point estimates are positive). In columns (3) and (4) we employ an aggregated version of the classification by lumping deeply or superficially islamized societies in one group and deeply or superficially christianized societies in another. It seems that exposure to Islam is more strongly associated with the evil eye belief, relative to Christianity. Finally, in columns (5) and (6) we drop the societies classified as heavily exposed to either of the four classical religions. Within this group of societies practicing traditional religions the inequality measures are strongly positively associated with the incidence of the evil eye belief, and the corresponding point estimates are close to the baseline from table 3 .

Environmental volatility. An important function of many supernatural beliefs is to explain misfortunes. To the extent that more volatile and risky environment generates more misfortunes to be explained, it might contribute to the emergence and diffusion of superstitions such as the evil eye belief, while at the same time producing higher inequality due to idiosyncratic wealth shocks. To address this potential issue we control for two proxies of environmental volatility available in the SCCS: pathogen stress, which captures

\footnotetext{
${ }^{23}$ For example, in a recent paper, Michalopoulos et al. (2012) argue that Islam emerged in response to a conflict environment caused by unequal regional agricultural endowments and offered economic and moral rules addressing wealth inequality and fostering undisrupted trade.
} 
Table 6: Evil eye, inequality, and classical religion. OLS estimates

\begin{tabular}{|c|c|c|c|c|c|c|}
\hline & (1) & $(2)$ & (3) & (4) & (5) & (6) \\
\hline Stratification dummy & $\begin{array}{c}0.596^{* *} \\
(0.300)\end{array}$ & & $\begin{array}{c}0.608^{* *} \\
(0.296)\end{array}$ & & $\begin{array}{c}0.726^{* *} \\
(0.332)\end{array}$ & \\
\hline Specialization & & $\begin{array}{c}0.319^{* *} \\
(0.149)\end{array}$ & & $\begin{array}{c}0.336^{* *} \\
(0.146)\end{array}$ & & $\begin{array}{c}0.399^{* *} \\
(0.173)\end{array}$ \\
\hline Deep Islam & $\begin{array}{l}1.403^{* * *} \\
(0.461)\end{array}$ & $\begin{array}{l}1.332^{* * *} \\
(0.458)\end{array}$ & $1.148^{* * *}$ & $1.077^{* *}$ & & \\
\hline Light Islam & $\begin{array}{c}0.762 \\
(0.654)\end{array}$ & $\begin{array}{c}0.677 \\
(0.659)\end{array}$ & $(0.428)$ & $(0.424)$ & $\begin{array}{c}0.762 \\
(0.695)\end{array}$ & $\begin{array}{c}0.641 \\
(0.713)\end{array}$ \\
\hline Deep Christianity & $\begin{array}{l}1.545^{* * *} \\
(0.571)\end{array}$ & $\begin{array}{l}1.366^{* *} \\
(0.577)\end{array}$ & $0.635^{*}$ & $0.608^{*}$ & & \\
\hline Light Christianity & $\begin{array}{c}0.438 \\
(0.406)\end{array}$ & $\begin{array}{c}0.454 \\
(0.402)\end{array}$ & $(0.358)$ & $(0.356)$ & $\begin{array}{c}0.455 \\
(0.399)\end{array}$ & $\begin{array}{c}0.467 \\
(0.393)\end{array}$ \\
\hline Buddhism & $\begin{array}{r}-0.821 \\
(0.552)\end{array}$ & $\begin{array}{r}-1.001^{*} \\
(0.585)\end{array}$ & $\begin{array}{r}-0.929^{*} \\
(0.551)\end{array}$ & $\begin{array}{r}-1.106^{*} \\
(0.576)\end{array}$ & & \\
\hline Hinduism & $\begin{array}{c}2.033^{* *} \\
(0.996)\end{array}$ & $\begin{array}{l}1.915^{*} \\
(1.045)\end{array}$ & $\begin{array}{c}1.946^{* *} \\
(0.964)\end{array}$ & $\begin{array}{r}1.835^{*} \\
(1.019)\end{array}$ & & \\
\hline Continental dummies & Yes & Yes & Yes & Yes & Yes & Yes \\
\hline Distance controls & Yes & Yes & Yes & Yes & Yes & Yes \\
\hline Development controls & Yes & Yes & Yes & Yes & Yes & Yes \\
\hline Observations & 186 & 186 & 186 & 186 & 147 & 147 \\
\hline Adjusted $R^{2}$ & 0.449 & 0.452 & 0.448 & 0.452 & 0.255 & 0.260 \\
\hline
\end{tabular}

the prevalence of various infectious diseases, and variation in mean annual rainfall. Neither variable turns out to be significant when included in the baseline specifications, and the coefficient estimates on inequality measures remain virtually intact. ${ }^{24}$

Falsification tests. One might wonder whether there is an intrinsic connection between inequality and superstitious beliefs in general, rather than just the evil eye belief. To explore this possibility we conduct a series of falsification tests using the prevalence of other magical beliefs on the left-hand side. The candidates were selected from the available

\footnotetext{
${ }^{24}$ The table of results is omitted. For definitions of the environmental variables see appendix B.
} 
data on the traditional theories of illness available for a subsample of SCCS (115 societies). Each of the following phenomena is coded on an ordinal scale from 1 to 4 based on whether it is considered to be an important cause of illness: mystical retribution, soul loss, spirit aggression, sorcery, witchcraft. ${ }^{25}$ For each belief, we estimate the baseline specifications from columns (3) and (6) in table 3 and report the results in table 7 . Reassuringly, none of the five supernatural beliefs is systematically related to inequality proxies. Hence, it does not seem like there is something about wealth differentiation that contributes to the formation of all sorts of superstitions, and the evil eye belief appears to be special in this regard, underpinning the connection between inequality and envy.

Table 7: Falsification tests: supernatural beliefs and inequality. OLS estimates

\begin{tabular}{lcccccc}
\hline & Evil Eye & Retribution & Soul loss & Spirits & Sorcery & Witchcraft \\
\hline Stratification dummy & $0.746^{* *}$ & -0.219 & -0.009 & 0.178 & 0.197 & -0.179 \\
& $(0.370)$ & $(0.173)$ & $(0.092)$ & $(0.180)$ & $(0.203)$ & $(0.209)$ \\
Adjusted $R^{2}$ & 0.350 & 0.031 & 0.107 & 0.180 & 0.223 & 0.278 \\
\hline Specialization & $0.319^{*}$ & -0.128 & 0.011 & 0.065 & 0.150 & -0.055 \\
& $(0.189)$ & $(0.081)$ & $(0.044)$ & $(0.086)$ & $(0.101)$ & $(0.108)$ \\
Adjusted $R^{2}$ & 0.345 & 0.038 & 0.107 & 0.176 & 0.236 & 0.274 \\
\hline Continental dummies & Yes & Yes & Yes & Yes & Yes & Yes \\
Distance controls & Yes & Yes & Yes & Yes & Yes & Yes \\
Development controls & Yes & Yes & Yes & Yes & Yes & Yes \\
Observations & 115 & 115 & 115 & 115 & 115 & 115 \\
\hline
\end{tabular}

Notes. a) Dependent variable is different for each column: (1) Evil eye belief on the 1-8 scale; columns (2)-(6) correspond to beliefs in the following phenomena as causes of illness, on the 1-4 scale: (2) mystical retribution; (3) soul loss; (4) spirit aggression; (5) sorcery; (6) witchcraft. b) Robust standard errors in parentheses. c) ${ }^{* * *},{ }^{* *}$, and $^{*}$ denote statistical significance at the 1, 5, and 10 percent level, respectively. d) Development controls refer to a full set of five development variables included in specifications (3) and (6) of table 3.

As follows from the conceptual framework of the previous section, the evil eye belief not just dictates the optimal "cautious" behavior, but also acts as a norm regulating the level of inequality in society. This issue relates to the debate in anthropological literature about the leveling versus stratifying effects of "institutionalized envy." Eric Wolf (1955), who coined the term, started the debate stressing the leveling forces, based on his explorations of Latin American peasantry. However, later studies, such as Cancian (1965) and Greenberg (1981), have empirically demonstrated that, although redistributive mechanisms, triggered in part by the fear of envy, seem to reduce inequality, they only operate to a certain extent. In

\footnotetext{
${ }^{25}$ See Murdock et al. (1978) and appendix B for definitions and details on these beliefs.
} 
fact, redistribution can even enhance stratification, not in terms of wealth differences, but through status and power acquired by the relatively rich individuals via sharing. ${ }^{26}$

To the extent that the evil eye belief acts as "leveler," the estimates reported above provide a lower bound for the coefficient on inequality. This "reverse causality" concern is partly alleviated since the employed measures of inequality are rather coarse: despite the plausible leveling properties of the belief, it is unlikely to render a stratified society egalitarian. To further mitigate this issue while also providing additional evidence on the fundamental correlates of the evil eye belief, the following subsection explores the relationship between the evil eye belief and the subsistence production mode. As explained below, the mode of production represents the technological basis of wealth distribution in society, and its choice is unlikely to be affected by the presence of the evil eye belief.

\subsection{Production mode, inequality, and the evil eye belief}

Social stratification is intimately linked to the type of subsistence economy, the two extremes being egalitarian foragers and highly stratified technologically advanced agricultural societies. An ambitious interdisciplinary project recently undertaken by a group of researchers employed individual-level data from small-scale societies to demonstrate that the production mode is systematically related to inequality and intergenerational transmission of wealth (Borgerhoff Mulder et al., 2009). ${ }^{27}$ The latter were shown to be substantial in pastoral and agricultural societies but modest among foragers and horticulturalists.

The key mechanism behind this result relies on the importance of different wealth types across production modes. Material wealth (such as livestock and land) is relatively more important in agro-pastoral economies and is at the same time easily transmitted from parents to children, conditional on rules of inheritance. In contrast, human capital (such as somatic wealth and skills) and social capital (such as network ties) are relatively more important in foraging and horticultural societies and are harder to transmit vertically. Higher rate of intergenerational transmission implies that random shocks to family wealth are more persistent, counteracting the tendency to mean reversion and raising the steadystate level of inequality. Note that technology (differential importance of wealth types) and institutions (rules of inheritance and redistributive norms) both contribute to differences in intergenerational mobility and inequality. Thus, we use production mode as a "deep" determinant of inequality that is unlikely to be affected by the evil eye belief.

\footnotetext{
${ }^{26}$ For an excellent analysis of traditional redistributive norms in Sub-Saharan Africa see Platteau (2014).

${ }^{27}$ For a detailed description of methodology and results of this study see the February 2010 issue of Current Anthropology (volume 51, number 1).
} 
First, we investigate the link between inequality and production mode across cultures to confirm the general finding of Borgerhoff Mulder et al. (2009). Available data allow to do this not just for the SCCS, but also for a larger sample in the Ethnographic Atlas which nests SCCS. ${ }^{28}$ For the SCCS, we use the variable "Subsistence Economy: Dominant Mode" which comprises the following categories: advanced agriculture (56 societies), horticulture (18), simple or shifting cultivation (51), domestic animals (15), exchange (1), fishing (17), gathering (13), and hunting (15). Following the definitional guidelines in Borgerhoff Mulder et al. (2009), we combine the second and third groups in one, "horticulturalists," and also lump together the last 4 groups as "foragers" to obtain a similar four-way classification. ${ }^{29}$

For the EA the four-way classification is constructed based on the variables measuring percentage dependence of the economy on gathering, hunting, fishing, animal husbandry, and agriculture, together with the data on the intensity of agriculture. The cases, for which the type of agriculture is unknown or several types of subsistence contribute equally, were omitted from the sample, to be consistent with the SCCS regressions. ${ }^{30}$ Otherwise, the type of subsistence economy was defined based on the most important contributing mode of production (50 percent and higher of the total).

To control for rules of inheritance we employ a categorical variable capturing the distribution of inheritance of land and movable property. The categories are as follows: no rights on land/movables, equal or relatively equal distribution, exclusive transfer (which comprises transfer to the "best qualified" individual, ultimogeniture, and primogeniture). Data on inheritance rules for movables and land are only available for subsamples of the SCCS (145 and 151 observations, respectively) and the EA (752 and 680 observations, respectively). ${ }^{31}$ The estimates are reported based on unified samples for which all of the relevant data are available.

As follows from columns (1)-(6) of table 8, evidence from the SCCS supports the main finding of Borgerhoff Mulder et al. (2009): agricultural and pastoral societies are on average more unequal compared to horticulturalists and foragers, where the latter category is taken as baseline. When stratification dummy is used as a measure of inequality, the formal test cannot reject the null that agriculture and pastoralism contribute equally to stratification. However, agricultural societies tend to be more technologically specialized compared to pastoral societies. Horticulturalists are closer to the omitted group of foragers, implying

\footnotetext{
${ }^{28}$ The only measure of inequality available in the EA is class stratification.

${ }^{29}$ One society in the "exchange" category are the Manus islanders, with fishing as secondary mode.

${ }^{30}$ Inclusion of these two categories as separate classes does not qualitatively alter the results. See figure C.1 in appendix $\mathrm{C}$ for the breakdown of both samples by subsistence production mode.

${ }^{31}$ See figure C.2 in appendix C for the breakdown of SCCS and EA societies based on this variable.
} 


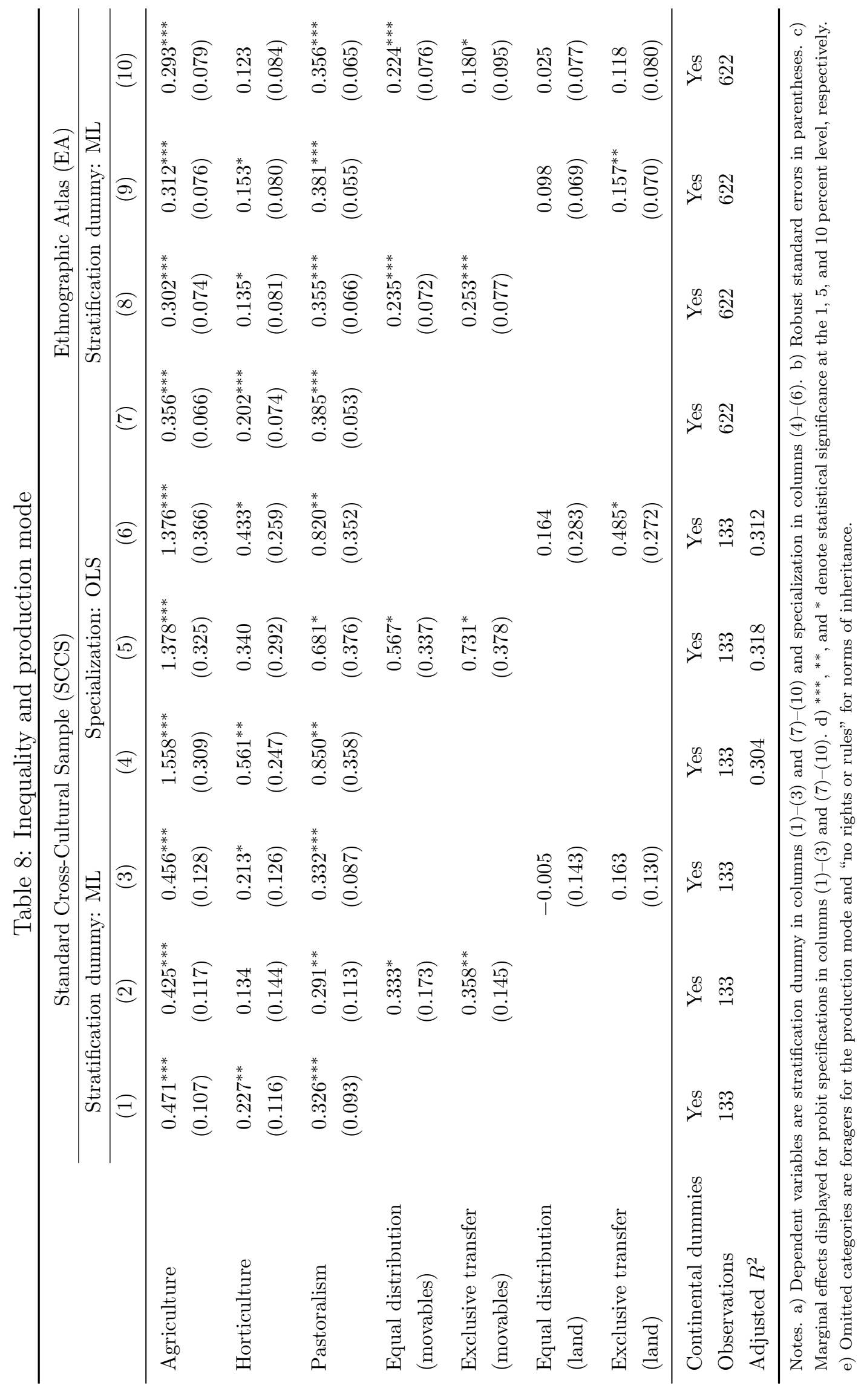


that the simplest cultivation technology does not yield a substantial increase in inequality. The rules of inheritance are also important correlates of inequality, consistent with the analysis of Borgerhoff Mulder et al. (2009). Rules that lead to more unequal distribution of inheritance are associated with higher stratification and specialization. Moreover, rules regulating the inheritance of movable property seem to be more important that those involving land. Columns (7)-(10) of table 8 support the above results in a broader sample of the Ethnographic Atlas.

To the extent that production mode differentially affects the degree of inequality in society, the evil eye belief should be more prevalent in agro-pastoral societies. Figure 3 and table 9 are consistent with this statement. That is, the incidence of the belief is substantially higher if the subsistence production mode is technologically more prone to perpetuate inequality.

Table 9 reveals several other patterns. First, the inclusion of distance controls makes a difference. This is not surprising, since, as mentioned above, they are good proxies for the diffusion of agriculture and domestication of animals, apart from the evil eye belief. Second, when inequality measures are included along with the production mode, they lose in magnitude, as expected. Nevertheless, stratification dummy remains marginally significant, while specialization remains significant at the 5 percent level.

On the one hand, this means that the link between inequality and the incidence of the evil eye belief is present even conditional on the mode of production, which is reassuring. On the other hand, the fact that "unequal" production modes seem to matter after controlling for finer measures of inequality may indicate that some of their other features are important. The conceptual framework of section 3 yields two possible explanations. First, material wealth which is more important in agro-pastoral societies is also highly visible and thus, is more likely to trigger comparisons and destructive envy. Second, material wealth such as livestock and crops is also highly vulnerable, making envious retaliation easier and the fear of destructive envy more pronounced. Hence, all three factors enabling destructive envy and the fear of it (inequality, strength of comparisons, and the ease of retaliation) seem to be more prominent in agro-pastoral societies and may be jointly driving the main finding of this exercise.

\subsection{Robustness checks}

In this section two types of robustness checks are carried out. First, the sample is trimmed in different ways to make sure the results are not sensitive to the inclusion of specific observations. Second, in order to deal in a more comprehensive way with the problem of 
Table 9: Evil eye belief and production mode. OLS estimates

\begin{tabular}{lcccccc}
\hline & $(1)$ & $(2)$ & $(3)$ & $(4)$ & $(5)$ & $(6)$ \\
\hline Agriculture & $1.692^{* * *}$ & $1.470^{* * *}$ & $1.146^{* *}$ & $1.010^{* *}$ & 0.736 & 0.554 \\
& $(0.423)$ & $(0.449)$ & $(0.479)$ & $(0.427)$ & $(0.453)$ & $(0.479)$ \\
Horticulture & 0.552 & 0.419 & 0.329 & 0.490 & 0.306 & 0.270 \\
& $(0.341)$ & $(0.350)$ & $(0.344)$ & $(0.368)$ & $(0.368)$ & $(0.364)$ \\
Pastoralism & $2.829^{* * *}$ & $2.607^{* * *}$ & $2.517^{* * *}$ & $1.941^{* * *}$ & $1.659^{* * *}$ & $1.666^{* * *}$ \\
& $(0.590)$ & $(0.604)$ & $(0.602)$ & $(0.539)$ & $(0.555)$ & $(0.548)$ \\
Stratification dummy & & 0.515 & & & $0.527^{*}$ & \\
& & $(0.318)$ & & & $(0.298)$ & \\
Specialization & & & $0.379^{* *}$ & & & $0.298^{* *}$ \\
& & & $(0.160)$ & & & $(0.147)$ \\
\hline Continental dummies & Yes & Yes & Yes & Yes & Yes & Yes \\
Distance controls & No & No & No & Yes & Yes & Yes \\
Observations & 186 & 186 & 186 & 186 & 186 & 186 \\
Adjusted $R^{2}$ & 0.246 & 0.253 & 0.269 & 0.413 & 0.421 & 0.427 \\
\hline
\end{tabular}

Notes. a) Dependent variable is the evil eye belief on the 1-8 scale. b) Robust standard errors in parentheses. c) ${ }^{* * *}$, **, and ${ }^{*}$ denote statistical significance at the 1,5 , and 10 percent level, respectively. d) Foragers are the omitted category for the production mode variable.

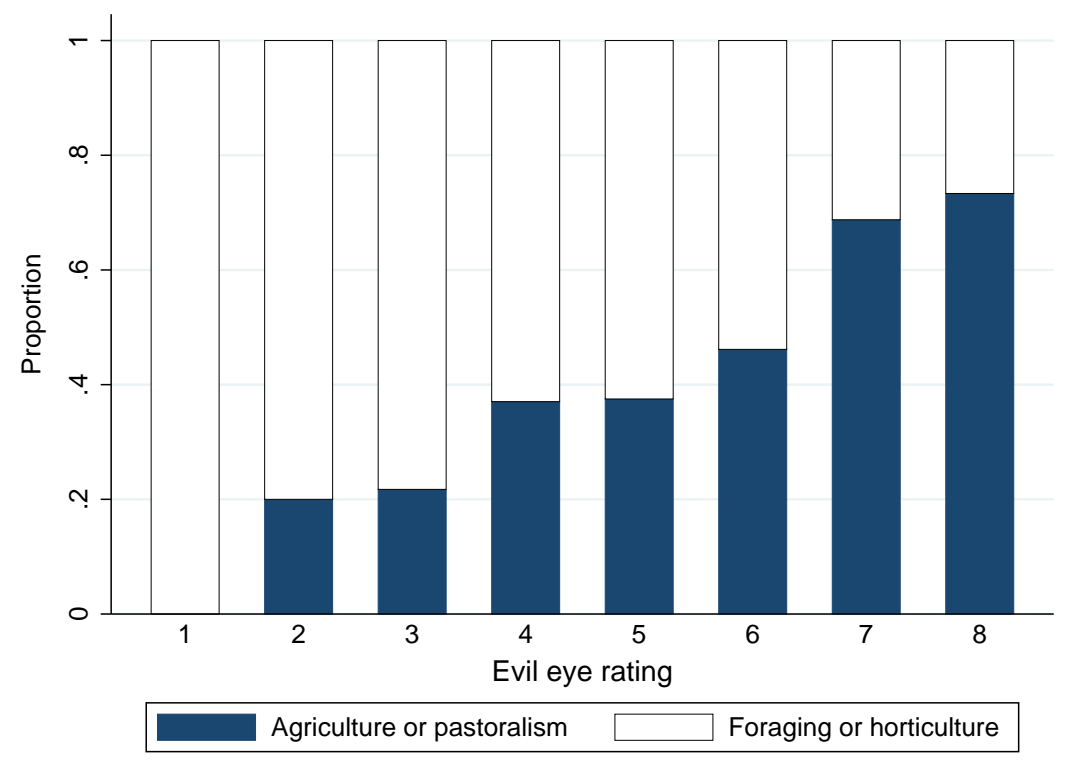

Figure 3: Production mode and the evil eye belief.

Note. The number of societies in each of the eight bins is $1,45,46,27,8,13,16$, and 30 , respectively. 
spatial autocorrelation we provide robust estimates of standard errors and estimate the spatial lag specifications of the baseline model using two alternative weights matrices.

Trimming the sample. The results are shown in table 10. Columns (1)-(4) present the estimates when societies pinpointed before 1800 are dropped from the sample, which leaves out cultures described based on historical documents or diaries of travelers rather than anthropological evidence. This restriction effectively reduces the sample by 12 observations and arguably increases comparability and reliability of the data. ${ }^{32}$ In columns (5)-(6) the model is estimated only for the Old World, leaving out the Americas thereby trimming the sample by 65 observations. Finally, in columns (7)-(10) we drop observations for which the evil eye belief rating is equal to 4 ("possibly absent") and 5 ("possibly present"), that is, the cases in which uncertainty about deciding on the presence or absence of the belief is the highest. Thus, in columns (7)-(10) the evil eye belief is absent for societies with rating 1-3 and present in societies with rating 6-8. Comparison with the baseline regression tables shows that the results are robust to all trimming strategies and are not driven by outliers.

Spatial autocorrelation. Although the original sampling strategy of Murdock and White (1969) aimed at reducing the spatial dependence of observations, it still remains an issue in the SCCS (Eff, 2004). We follow several strategies to demonstrate the robustness of baseline results to this potential problem. First, continental dummies and distance controls are included in all specifications. Second, we report the standard errors adjusted for spatial correlation in table 11. In columns (3)-(4) clustered standard errors are shown. To account for potential interdependencies in the error terms across societies we cluster the standard errors at one of two levels: language region and language family. Language region is a coarse measure of common language origin that comprises 10 categories, while language family is a finer subdivision into 47 categories (Burton, 1999). ${ }^{33}$

Columns (5)-(7) show the standard errors corrected using the methodology of Conley (1999) that does not impose an a priori structure on the type of spatial dependence. Specifically, asymptotic covariance matrices are estimated as weighted averages of sample autocovariances, where the weight for each term is the product of weight functions in each dimension that decline linearly and are zero beyond specified cutoff distances. To

\footnotetext{
${ }^{32}$ Specifically, the following cultures are dropped (date of pinpointing in parentheses): Babylonians (1750 B.C.), Hebrews (621 B.C.), Romans (110), Khmer (1292), Aztec (1520), Inca (1530), Tupinamba (1550), Huron (1634), Callinago (1650), Micmac (1650), Natchez (1718), Abipon (1750). Another strategy is to include the date of pinpointing explicitly as an additional regressor. This does not change any of the reported results, and the new regressor itself turns out insignificant in all baseline specifications.

${ }^{33}$ Clustering at the continental level yields qualitatively similar results which are not reported.
} 


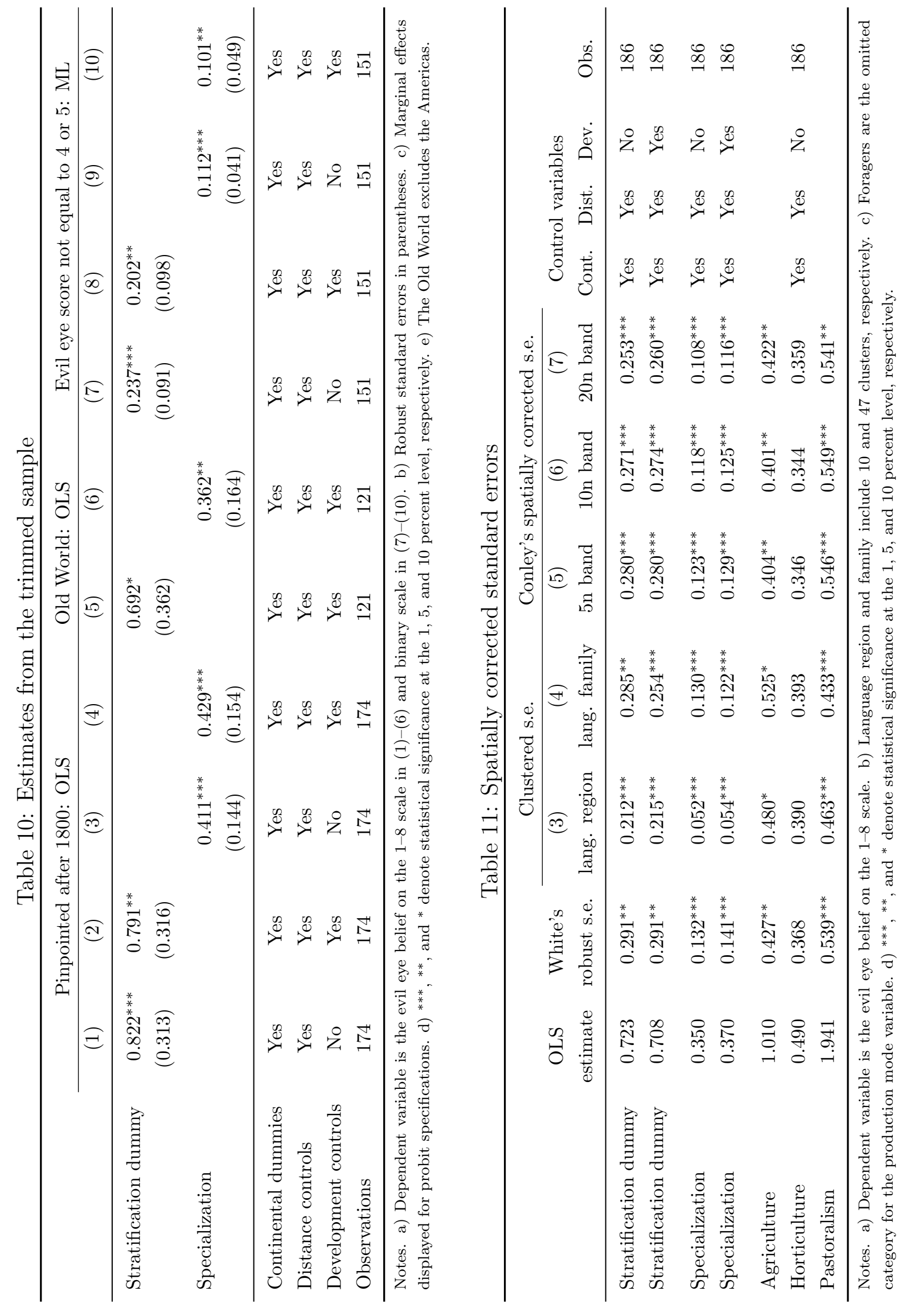


define these cutoffs we first use the Mercator projection to get the coordinates for each SCCS society on the Euclidean plane. We then compute an average distance band which "forces" each society to have a certain minimal number of neighbors within that band. This distance band is then used as cutoff in each dimension to calculate the spatially corrected standard errors. Specifically, in column (5) it is the average distance band that covers at least 5 neighbors for each society, while in columns (6) and (7) the number of neighbors is increased to 10 and 20, respectively. In general, table 11 reveals that adjustment of standard errors for potential spatial autocorrelation does not change the qualitative results and, in fact, White's robust standard errors reported throughout the paper turn out to be the most conservative in the majority of cases.

Finally, it is possible that distance controls do not fully account for the direct crosscultural transmission of the belief. To explore the transmission mechanism more closely we estimate the following spatial lag specification of the model: ${ }^{34}$

$$
\text { eye }=\alpha_{S}+\rho_{S} \mathbf{W} \text { eye }+\beta_{S} \text { inequality }+\mathbf{X} \Gamma_{S}+\mathbf{D} \Delta_{S}+\varepsilon_{S},
$$

where eye and inequality now denote the vectors of observations for these two variables, $\mathbf{X}$ and $\mathbf{D}$ are matrices of control variables and continental dummies, $\mathbf{W}$ is the (row standardized) spatial weights matrix, Weye is the spatial lag of the evil eye belief variable and the subscript $S$ stands for "spatial." To proceed one has to specify the spatial weights matrix $\mathbf{W}$. We use two alternative matrices. The first one, $\mathbf{W}_{G}$, is based on geographical (great circle) distances between societies. In particular, each entry of the matrix is the (row standardized) squared inverse of the distance between corresponding societies. The second matrix, $\mathbf{W}_{L}$, is based on phylogenetic distances between societies. This matrix of proximity between languages spoken by the SCCS societies was constructed by Eff (2008) based on the data from Ethnologue. The proximity between each pair of languages is calculated as the distance from the panhuman root of the language tree to the nearest common ancestor of those two languages. ${ }^{35}$ These distance matrices are designed to account for the effects of descent and cultural borrowing on the incidence of the evil eye belief. The spatial lag models are estimated via maximum likelihood (Anselin and Hudak, 1992).

Table 12 shows the estimation results. In panel A the spatial weights matrix is based on geographic distances, while in panel $\mathrm{B}$ it is based on phylogenetic distances. In all specifications, apart from column (5), the spatial lag of the evil eye belief is insignificant,

\footnotetext{
${ }^{34}$ Estimation of the spatial error model yields very similar results. The spatial lag model seems more appropriate given the possibility of direct transmission through cross-cultural contact.

${ }^{35}$ See Eff (2008) for details. The matrix is available for download in Excel format at Anthon Eff's website: http://www.mtsu.edu/ eaeff/downloads/SCCSprox.xls.
} 
Table 12: Spatial lag specifications. ML estimates

\begin{tabular}{|c|c|c|c|c|c|c|}
\hline A. Geographic weights & (1) & $(2)$ & (3) & $(4)$ & (5) & (6) \\
\hline Stratification dummy & $\begin{array}{c}0.720^{* *} \\
(0.285)\end{array}$ & $\begin{array}{c}0.706^{* *} \\
(0.281)\end{array}$ & & & & \\
\hline Specialization & & & $\begin{array}{l}0.349^{* * *} \\
(0.129)\end{array}$ & $\begin{array}{l}0.369^{* * *} \\
(0.137)\end{array}$ & & \\
\hline Agriculture & & & & & $\begin{array}{l}1.654^{* * *} \\
(0.410)\end{array}$ & $\begin{array}{c}1.012^{* *} \\
(0.415)\end{array}$ \\
\hline Horticulture & & & & & $\begin{array}{c}0.564^{*} \\
(0.335)\end{array}$ & $\begin{array}{c}0.496 \\
(0.359)\end{array}$ \\
\hline Pastoralism & & & & & $\begin{array}{l}2.769^{* * *} \\
(0.562)\end{array}$ & $\begin{array}{l}1.947^{* * *} \\
(0.520)\end{array}$ \\
\hline Spatial lag & $\begin{array}{c}-0.325 \\
(1.126)\end{array}$ & $\begin{array}{c}-0.236 \\
(1.073)\end{array}$ & $\begin{array}{c}-0.309 \\
(1.115)\end{array}$ & $\begin{array}{c}-0.215 \\
(1.060)\end{array}$ & $\begin{array}{l}0.763^{* * *} \\
(0.227)\end{array}$ & $\begin{array}{r}-0.485 \\
(1.228)\end{array}$ \\
\hline LM-test $p$-value & 0.825 & 0.866 & 0.832 & 0.876 & 0.020 & 0.761 \\
\hline B. Phylogenetic weights & (1) & $(2)$ & $(3)$ & $(4)$ & $(5)$ & (6) \\
\hline Stratification dummy & $\begin{array}{c}0.730^{* *} \\
(0.285)\end{array}$ & $\begin{array}{c}0.718^{* *} \\
(0.282)\end{array}$ & & & & \\
\hline Specialization & & & $\begin{array}{l}0.350^{* * *} \\
(0.129)\end{array}$ & $\begin{array}{l}0.370^{* * *} \\
(0.137)\end{array}$ & & \\
\hline Agriculture & & & & & $\begin{array}{l}1.650^{* * *} \\
(0.412)\end{array}$ & $\begin{array}{c}1.008^{* *} \\
(0.417)\end{array}$ \\
\hline Horticulture & & & & & $\begin{array}{c}0.626^{*} \\
(0.332)\end{array}$ & $\begin{array}{c}0.496 \\
(0.358)\end{array}$ \\
\hline Pastoralism & & & & & $\begin{array}{l}2.704^{* * *} \\
(0.566)\end{array}$ & $\begin{array}{l}1.926^{* * *} \\
(0.525)\end{array}$ \\
\hline Spatial lag & $\begin{array}{c}0.257 \\
(0.327)\end{array}$ & $\begin{array}{c}0.272 \\
(0.318)\end{array}$ & $\begin{array}{c}0.224 \\
(0.501)\end{array}$ & $\begin{array}{c}0.243 \\
(0.326)\end{array}$ & $\begin{array}{l}0.673^{* * *} \\
(0.187)\end{array}$ & $\begin{array}{c}0.146 \\
(0.349)\end{array}$ \\
\hline LM-test $p$-value & 0.487 & 0.455 & 0.550 & 0.508 & 0.005 & 0.706 \\
\hline Continental dummies & Yes & Yes & Yes & Yes & Yes & Yes \\
\hline Distance controls & Yes & Yes & Yes & Yes & No & Yes \\
\hline Development controls & No & Yes & No & Yes & No & No \\
\hline Observations & 186 & 186 & 186 & 186 & 186 & 186 \\
\hline
\end{tabular}


and the estimates of interest are very close to those reported earlier. Column (5) is the only specification in table 12 which does not include distance controls. Hence, the analysis implies that the inclusion of distance controls effectively takes care of spatial dependence, at least as captured by the spatial lag specifications with two alternative weights matrices.

\section{Concluding remarks}

This paper contributes to the growing literature on the economic origins of culture by constructing a framework for understanding a particular cultural phenomenon, the evil eye belief. We argue that this superstition emerged and persisted as a useful rule of thumb approximating rational envy-avoidance behavior under conditions in which destructive envy is a real threat, that is, when wealth inequality is high and formal institutions enforcing property rights are missing.

Evidence from the Standard Cross-Cultural Sample supports the main theoretical prediction. The incidence of the evil eye belief is substantially higher in unequal, technologically specialized societies. This result is robust to measures of spatial and cross-cultural diffusion, indicators of cultural complexity, exposure to classical religion, and continental dummies. The connection between the evil eye belief and inequality is stronger in weakly institutionalized societies. Furthermore, the evil eye belief is more likely to be found in agro-pastoral societies that sustain higher levels of inequality and rely more on visible and vulnerable material wealth compared to foragers and horticulturalists. We find no evidence that inequality is systematically related to any other supernatural beliefs which are not explicitly connected to the notion of destructive envy.

Overall, this paper offers a novel link between early economic development and culture through the emotion of envy. Wealth differentiation contributed to the emergence of envy-avoidance culture which has been useful in a weakly institutionalized environment. Curiously, since culture tends to persists even after the relevant underlying conditions change, in parts of the modern world where it is no longer useful, the evil eye belief may plausibly act as a brake on economic development by discouraging wealth accumulation and social mobility. 


\section{Appendices}

\section{A A Model of the rational fear of envy}

The following model identifies the conditions that make envy-avoidance behavior the optimal response to anticipated envious retaliation in a perfect-information world. As argued in section 3, the evil eye belief as a heuristic device prescribing envy-avoidance behavior is useful and will persist in such an environment under uncertainty and bounded rationality. ${ }^{36}$

Environment. Consider two agents who may be thought of as representatives of equal-sized homogeneous groups of people. They differ only in the amount of broadly defined initial endowments, $K_{i}, i=1,2$. The ratio $k \equiv K_{1} / K_{2} \leqslant 1$ captures the degree of initial inequality: Agent 1 is "poor" and Agent 2 is "rich." They interact in the following two-stage game (see figure 1).

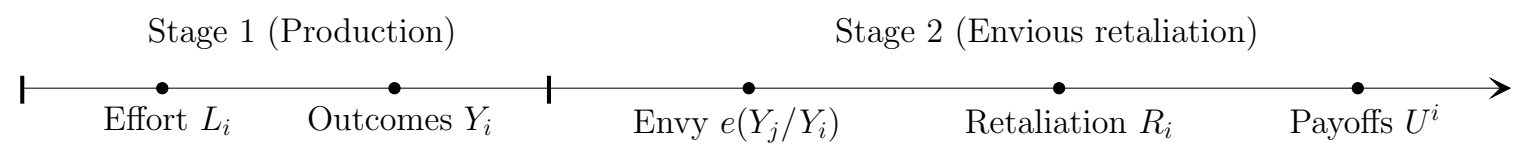

Figure A.1: Timing of events in the envy game.

In the first stage, each agent has a unit of time that needs to be split between production and leisure. A fraction $L_{i} \in[0,1]$ spent on production yields $Y_{i}=K_{i} L_{i}$ units of the final product and imposes a cost $h\left(L_{i}\right)$ of foregone leisure, where $h^{\prime}\left(L_{i}\right)>0, h^{\prime \prime}\left(L_{i}\right) \geqslant 0$. Unequal outcomes of the production stage cause envy on part of the agent with a smaller outcome.

In particular, Agent $i$ 's envy is generated according to the following function ${ }^{37}$ :

$$
e\left(y_{i}\right)>0, e^{\prime}\left(y_{i}\right)>0, e^{\prime \prime}\left(y_{i}\right)>0, \quad \text { if } \quad y_{i} \equiv Y_{j} / Y_{i}>1, \quad i, j=1,2, \quad i \neq j .
$$

If $y_{i} \leqslant 1$, Agent $i$ experiences no envy, that is, $e\left(y_{i}\right)=0$, while Agent $j$ does. Envy can be assuaged through "retaliation" that is costly for the envious agent and harmful for the envied. In particular, if Agent $i$ is envious, the amount of retaliation $R_{i}$ reduces his envy by a fraction $F\left(R_{i}\right) \in[0,1)$ at a cost $C\left(R_{i}\right)$ and causes disutility $G\left(R_{i}\right)$ to Agent $j$.

\footnotetext{
${ }^{36}$ The model is based on Mui (1995) who explores the incentives to adopt technological innovations under the threat of envious retaliation. There are, however, two important departures from his framework. First, inequality of initial endowments is introduced, crucial for generating the main prediction of the theory. Second, rather than making a costless binary decision of adopting or rejecting an exogenously given new technology, individuals are choosing their continuous effort levels and care about foregone leisure.

${ }^{37}$ One could assume an arbitrary exogenous envy threshold $\bar{y}$ instead of unity. More important for the analysis is the endogenous tolerance threshold, as described below.
} 
Assume that for any $R_{i} \geqslant 0$

$$
\begin{aligned}
& F(0)=0<F^{\prime}\left(R_{i}\right)<\infty, F^{\prime \prime}\left(R_{i}\right)<0 ; \\
& C(0)=0<C^{\prime}\left(R_{i}\right)<\infty, C^{\prime \prime}\left(R_{i}\right) \geqslant 0 ; \\
& G(0)=0<G^{\prime}\left(R_{i}\right), G^{\prime \prime}\left(R_{i}\right) \geqslant 0 .
\end{aligned}
$$

The total payoff generated at the end of the game is assumed to be additively separable across all benefits and costs:

$$
U_{i}=v\left(Y_{i}\right)-\theta e\left(Y_{j} / Y_{i}\right)\left(1-F\left(R_{i}\right)\right)-C\left(R_{i}\right)-G\left(R_{j}\right)-h\left(L_{i}\right),
$$

where $i, j=1,2, i \neq j$. The function $v\left(Y_{i}\right)$ is the utility of own consumption and satisfies the standard conditions: $v^{\prime}\left(Y_{i}\right)>0, v^{\prime \prime}\left(Y_{i}\right)<0$. Parameter $\theta$ captures the strength of envy, or the importance of relative standing. It may be related to social norms as well as the visibility of consumption and productive assets.

We are looking for the subgame perfect equilibrium of this simple dynamic game using backward induction. At stage two, productive effort is sunk and the only decision to be made is whether to engage in envy-reducing behavior or not. In particular, Agent $i$ chooses $R_{i}$ to solve the maximization problem

$$
\max _{R_{i}}\left\{-\theta e\left(y_{i}\right)\left(1-F\left(R_{i}\right)\right)-C\left(R_{i}\right)\right\} \quad \text { s.t. } \quad R_{i} \geqslant 0 .
$$

Given assumptions (A1) and (A2), the above function is concave in $R_{i}$ and the first-order conditions yield the unique global optimum, $R_{i}^{*}$.

Lemma 1 (Optimal retaliation). The optimal envy-reducing effort by Agent $i$ is

$$
R_{i}^{*}= \begin{cases}R_{i}^{*}\left(\theta, y_{i}\right), & \text { if } e\left(y_{i}\right)>\frac{1}{\theta} \cdot \frac{C^{\prime}(0)}{F^{\prime}(0)} \\ 0, & \text { otherwise }\end{cases}
$$

where $R_{i}^{*}\left(\theta, y_{i}\right)$ is strictly increasing in $\theta$ and $y_{i}$ and is implicitly given by

$$
\theta e\left(y_{i}\right) F^{\prime}\left(R_{i}^{*}\right)=C^{\prime}\left(R_{i}^{*}\right) .
$$

The optimal retaliation function has two important features. First, the decision to engage in retaliation depends on the level of posterior inequality, $y_{i}$. Specifically, if this ratio is low enough, Agent $i$ finds it optimal to tolerate envy peacefully. The endogenous tolerance threshold depends on the strength of envy and the parameters of the cost function, envy function, and envy-reduction technology. Second, if Agent $i$ finds it optimal to retaliate, the amount of retaliation is increasing in $\theta$ and $y_{i}$. 
Rather than proceeding with the model in general form, we impose simple functional form assumptions that deliver closed-form solutions and convey the simple intuition of the envy game. Specifically, assume that the envy-reduction function takes the simple form

$$
F\left(R_{i}\right)=\frac{R_{i}}{1+R_{i}},
$$

which satisfies (A2), and the cost function is linear, $C\left(R_{i}\right)=R_{i} / \tau$, where $\tau$ is the inverse marginal cost of retaliation that may be broadly interpreted as an institutional parameter, capturing, for example, the quality of private property rights protection or the likelihood or severity of punishment for retaliating. In the context of the empirical analysis to follow, a different interpretation of $\tau$ is particularly relevant, since formal institutions and legal system are virtually nonexistent in the preindustrial small-scale societies. Specifically, retaliation is less costly if the coveted wealth is more vulnerable, that is, easily harmed. ${ }^{38}$

Under the stated functional form assumptions equation (A5) becomes

$$
R_{i}^{*}=\left\{\begin{array}{lll}
0, & \text { if } & e\left(y_{i}\right) \leqslant 1 / \tau \theta \\
\sqrt{\tau \theta e\left(y_{i}\right)}-1, & \text { if } & e\left(y_{i}\right)>1 / \tau \theta,
\end{array}\right.
$$

where $1 / \tau \theta$ is the tolerance for inequality threshold depending on the importance of relative standing, $\theta$, and the ease of retaliation, $\tau$.

Assume furthermore that the utility of consumption is logarithmic, $v\left(Y_{i}\right)=\ln \left(Y_{i}\right)$, the disutility of effort and retaliation is linear, $h\left(L_{i}\right)=L_{i}$ and $G\left(R_{j}\right)=R_{j}$, and the envy function is quadratic, when positive, that is, $e\left(y_{i}\right)=\left(y_{i}-1\right)^{2}$, if $y_{i}>1$. Given these additional assumptions, it is straightforward to solve for the best responses of both agents. Specifically, at the production stage the forward-looking Agent $i$ is solving the following problem:

$$
\max _{Y_{i}}\left\{U_{i}=\ln \left(Y_{i}\right)-\frac{\theta e\left(Y_{j} / Y_{i}\right)}{1+R_{i}^{*}}-R_{i}^{*} / \tau-R_{j}^{*}-\frac{Y_{i}}{K_{i}}\right\} \quad \text { s.t. } 0 \leqslant Y_{i} \leqslant K_{i},
$$

where $R_{i}^{*}$ and $R_{j}^{*}$ are given by (A8). The best responses then take a very simple form, as established in the following lemma.

Lemma 2 (Best responses). The best response function of Agent $i$ is given by

$$
Y_{i}^{*}\left(Y_{j}\right)=\min \left\{K_{i}, \gamma Y_{j}\right\}, \quad i, j=1,2, \quad i \neq j
$$

where $\gamma \equiv 1+1 / \sqrt{\tau \theta}$.

\footnotetext{
${ }^{38} \mathrm{As}$ argued in section 4.3, agro-pastoral societies rely heavily on material wealth such as livestock and crops that are easily damaged or stolen. Hence, envious retaliation is less costly and the fear of it is likely to be greater in such societies.
} 

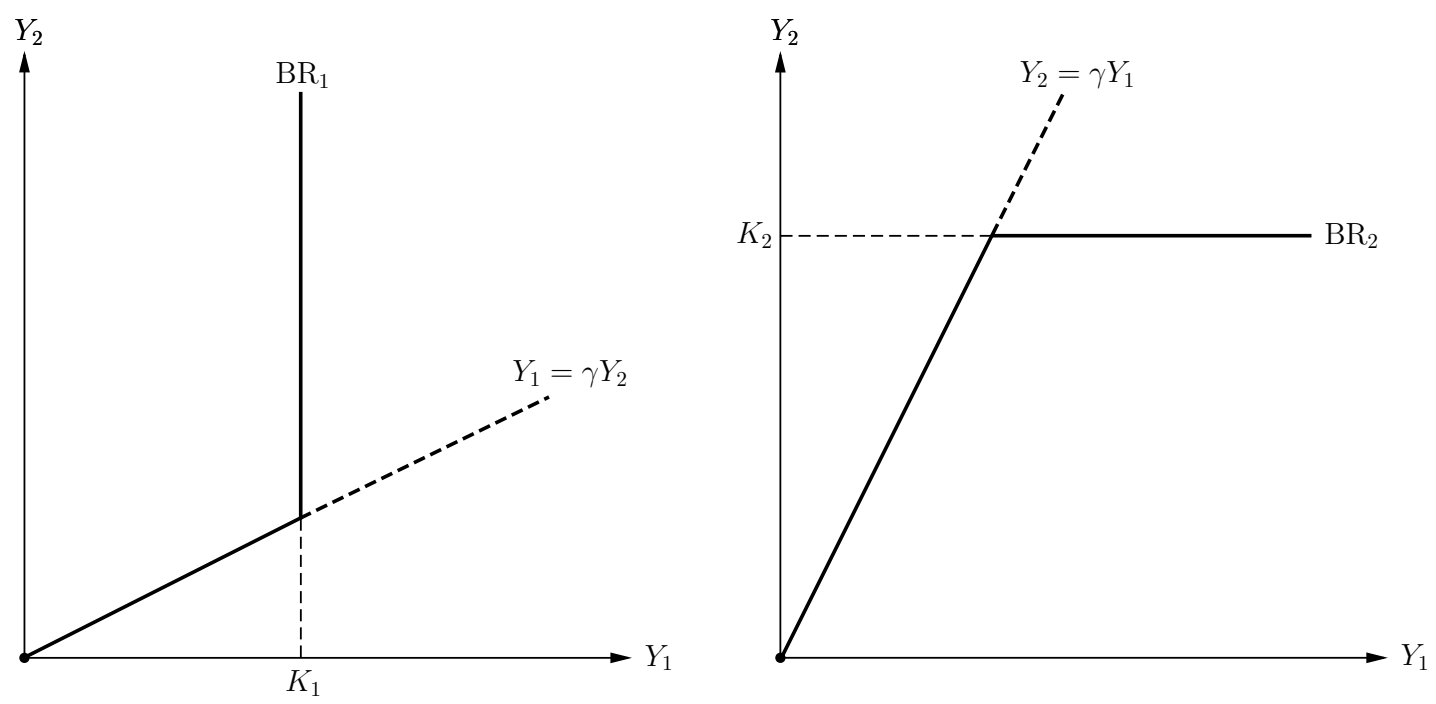

Figure A.2: Best response functions of Agent 1 (left) and Agent 2 (right).

So, in this setup it is never optimal to allow retaliation. As depicted in figure 2, the best response function consists of two segments. Specifically, if the output of Agent $j$ is large enough, Agent $i$ works full time, without fearing aggression. If, on the contrary, $Y_{j}$ is low, Agent $i$ finds it optimal to work only part-time since otherwise he will incite destructive envy.

Depending on parameter values one of the two alternative equilibria emerges. In the "no fear equilibrium" both agents work full time and there is no envious retaliation (destructive envy is not binding). In the "fear equilibrium" the poor agent works full time while the rich agent is at the corner solution and underinvests in order to avoid envious retaliation. More precisely, the following proposition holds.

Proposition 1 (Equilibrium). There exists a unique subgame perfect equilibrium $\left(Y_{1}^{*}, Y_{2}^{*}\right)$ of the game:

$$
\left(Y_{1}^{*}, Y_{2}^{*}\right)= \begin{cases}\left(K_{1}, K_{2}\right), & \text { if } k \geqslant 1 / \gamma \\ \left(K_{1}, \gamma K_{1}\right), & \text { otherwise }\end{cases}
$$

where $\gamma \equiv 1+1 / \sqrt{\tau \theta}$.

The two situations are depicted in figure A.3. The takeaway from proposition 1 is that the rational fear of envy and underinvestment emerge when fundamental inequality is sufficiently high, given the retaliation cost parameter $\tau$ (vulnerability of wealth, property rights protection) and the strength of concern for relative standing $\theta$. 

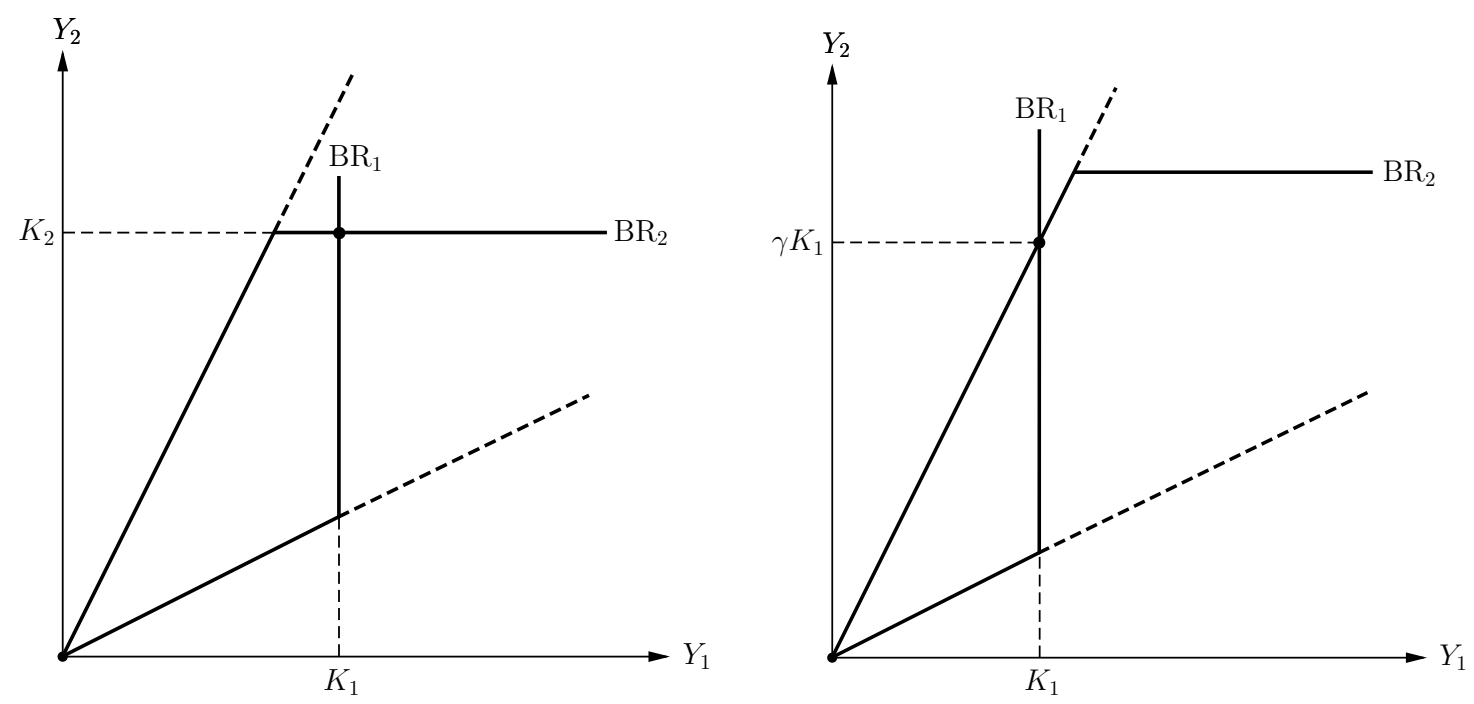

Figure A.3: Equilibria of the envy game, without (left) and with (right) the fear of envy.

It seems plausible that in such a setup there is scope for ex-ante Pareto improving redistribution. In fact, the following proposition holds.

Proposition 2 (Optimal transfer of Agent 2). Assume that $k<1 / \gamma$, that is, the economy is in the fear equilibrium, and let $T$ be the size of endowment transfer from Agent 2 to Agent 1 before production takes place. Let $\bar{T} \equiv\left(K_{2}-\gamma K_{1}\right) /(1+\gamma)$ denote the minimal transfer that would change the outcome of the game to the no fear equilibrium. Then, the optimal ex-ante transfer from the point of view of Agent 2 is

$$
T^{*}= \begin{cases}K_{2}-0.5\left(K_{1}+K_{2}\right)(\sqrt{\gamma(\gamma+4)}-\gamma), & \text { if } k<(\sqrt{1+4 / \gamma}-1) / 2 \\ 0, & \text { otherwise }\end{cases}
$$

Moreover, $T^{*}$ is increasing in $\tau$ and $\theta$, when positive, and $T^{*}<\bar{T}$.

Clearly, Agent 1 always benefits from a transfer since he experiences less envy in equilibrium. However, for Agent 2 it will only be optimal to share his endowment with Agent 1 if the fear constraint associated with envious retaliation is strong enough, that is, inequality is high and/or the tolerance threshold is low. Otherwise, the benefit of alleviating the fear constraint does not cover the cost of giving away part of endowment and thus reducing the productivity of labor. Furthermore, optimal redistribution never leads to an escape from the fear equilibrium. Hence, although redistributive mechanisms can improve efficiency, the main result of proposition 1 is robust to allowing optimal ex-ante transfers. 


\section{A.1 Proofs}

Lemma 1. Equations (A5) and (A6) are just the first-order conditions of the maximization problem (A4). Given assumptions (A1) and (A2), the left-hand side of (A6) is strictly increasing in $\theta$ and $y_{i}$ and strictly decreasing in $R_{i}^{*}$, while the right-hand side is increasing in $R_{i}^{*}$. It follows immediately that $R_{i}^{*}\left(\theta, y_{i}\right)$ is strictly increasing in its arguments.

Lemma 2. Agent $i$ is solving (A9) subject to (A8). He is choosing one of the following four options. First, consider the case, in which there is no retaliation on either side, that is, $R_{i}^{*}=R_{j}^{*}=0$, and Agent $i$ is envious. Under quadratic envy function this holds iff $Y_{j} / \gamma \leqslant Y_{i} \leqslant Y_{j}$, where $\gamma \equiv 1+1 / \sqrt{\tau \theta}$. Note that, due to the resource constraint $Y_{i} \leqslant K_{i}$, this option is only feasible if $K_{i} \geqslant Y_{j} / \gamma$. The utility function of Agent $i$ in this case is given by $U_{i}=\ln \left(Y_{i}\right)-\theta\left(Y_{j} / Y_{i}-1\right)^{2}-Y_{i} / K_{i}$. It is strictly concave in $Y_{i}$ and yields the optimum $Y_{i}^{*}\left(Y_{j}\right)=\min \left\{K_{i}, Y_{j}\right\}$, since $U_{i}^{\prime}=1 / Y_{i}-1 / K_{i}+2 \theta\left(Y_{j} / Y_{i}-1\right) \cdot Y_{j} / Y_{i}^{2} \geqslant 0$ for any $Y_{i} \leqslant K_{i}$. Note that the left derivative at point $Y_{i}=Y_{j}$ is $U_{i}^{\prime}\left(Y_{j}^{-}\right)=1 / Y_{j}-1 / K_{i}$ and the right derivative at point $Y_{i}=Y_{j} / \gamma$ is $U_{i}^{\prime}\left(Y_{j} / \gamma^{+}\right)=\gamma / Y_{j}-1 / K_{i}+2 \sqrt{\theta / \tau} \cdot \gamma^{2} / Y_{j}$.

Second, consider the case, in which $R_{i}^{*}=R_{j}^{*}=0$, and Agent $j$ is envious. This holds iff $Y_{j} \leqslant Y_{i} \leqslant \gamma Y_{j}$, and is only feasible if $K_{i} \geqslant Y_{j}$. The utility function in this case is given by $U_{i}=\ln \left(Y_{i}\right)-Y_{i} / K_{i}$. It is strictly concave in $Y_{i}$ and yields the optimum $Y_{i}^{*}\left(Y_{j}\right)=\min \left\{K_{i}, \gamma Y_{j}\right\}$, since $U_{i}^{\prime}=1 / Y_{i}-1 / K_{i}$ and $Y_{i} \leqslant K_{i}$. Note that the left derivative at point $Y_{i}=\gamma Y_{j}$ is $U_{i}^{\prime}\left(\gamma Y_{j}^{-}\right)=1 / \gamma Y_{j}-1 / K_{i}$ and the right derivative at point $Y_{i}=Y_{j}$ is $U_{i}^{\prime}\left(Y_{j}^{+}\right)=1 / Y_{j}-1 / K_{i}=U_{i}^{\prime}\left(Y_{j}^{-}\right)$, that is, $U_{i}$ is differentiable at $Y_{i}=Y_{j}$ and $U_{i}^{\prime}\left(Y_{j}\right)>0 \Leftrightarrow K_{i}>Y_{j}$. Putting together the first two cases (no retaliation on either side) yields the optimum $Y_{i}^{*}\left(Y_{j}\right)=\min \left\{K_{i}, \gamma Y_{j}\right\}$, provided that $K_{i} \geqslant Y_{j} / \gamma$.

Third, consider the case, in which Agent $i$ is envious and retaliates, that is, $R_{i}^{*}>0$. This happens if $Y_{i}<Y_{j} / \gamma$, and is the only option if $K_{i}<Y_{j} / \gamma$. In this case $1+R_{i}^{*}=\sqrt{\tau \theta}\left(Y_{j} / Y_{i}-1\right)$, and the utility function becomes $U_{i}=$ $\ln \left(Y_{i}\right)-2 \sqrt{\theta / \tau}\left(Y_{j} / Y_{i}-1\right)+1 / \tau-Y_{i} / K_{i}$. It is strictly concave in $Y_{i}$ and yields the optimum $Y_{i}^{*}=\min \left\{K_{i}, Y_{j} / \gamma\right\}, \operatorname{since}$ $U_{i}^{\prime}=1 / Y_{i}-1 / K_{i}+2 \sqrt{\theta / \tau} \cdot Y_{j} / Y_{i}^{2}>0$ for any $Y_{i} \leqslant K_{i}$. Note that $U_{i}^{\prime}\left(Y_{j} / \gamma^{-}\right)=\gamma / Y_{j}-1 / K_{i}+2 \sqrt{\theta / \tau} \cdot \gamma^{2} / Y_{j}=U_{i}^{\prime}\left(Y_{j} / \gamma^{+}\right)$. Hence, $U_{i}$ is differentiable at $Y_{i}=Y_{j} / \gamma$ and $U_{i}^{\prime}\left(Y_{j} / \gamma\right)>0$ if $K_{i}>Y_{j} / \gamma$.

Fourth, consider the case, in which Agent $j$ is envious and retaliates, that is, $R_{j}^{*}>0$. This holds iff $Y_{i}>\gamma Y_{j}$, and is only feasible if $K_{i}>\gamma Y_{j}$. In this case $1+R_{j}^{*}=\sqrt{\tau \theta}\left(Y_{i} / Y_{j}-1\right)$, and the utility function is $U_{i}=\ln \left(Y_{i}\right)-\sqrt{\tau \theta}\left(Y_{i} / Y_{j}-1\right)-Y_{i} / K_{i}$. It is strictly concave in $Y_{i}$ and yields the optimum $Y_{i}^{*}=\gamma Y_{j}$, since $U_{i}^{\prime}\left(\gamma Y_{j}^{+}\right)=1 / \gamma Y_{j}-\sqrt{\tau \theta} / Y_{j}-1 / K_{i}=(1-\gamma \sqrt{\tau \theta}) / \gamma Y_{j}-1 / K_{i}<$ 0 given that $1-\gamma \sqrt{\tau \theta}=-1 / \sqrt{\tau \theta}<0$. This implies that it is never optimal for Agent $i$ to allow retaliation on part of Agent $j$. Note also that $U_{i}^{\prime}\left(\gamma Y_{j}^{+}\right) \neq U_{i}^{\prime}\left(\gamma Y_{j}^{-}\right)$, that is, $U_{i}$ has a kink at point $Y_{i}=\gamma Y_{j}$. The one-sided derivatives at this point are of different signs iff $K_{i}>\gamma Y_{j}$.

If $K_{i}<Y_{j} / \gamma$, the only available option is the third one and, hence, $Y_{i}^{*}\left(Y_{j}\right)=K_{i}$. If $Y_{j} / \gamma \leqslant K_{i}<Y_{j}$, then options 3 and 1 are available. Given the properties of the utility function, he chooses option 1 , again yielding $Y_{i}^{*}\left(Y_{j}\right)=K_{i}$. If $Y_{j} \leqslant K_{i}<\gamma Y_{j}$, options 1-3 are available, now option 2 giving the interior optimum $Y_{i}^{*}\left(Y_{j}\right)=K_{i}$. Finally, if $K_{i} \geqslant \gamma Y_{j}$, all four options are available and the optimum is at the kink point $Y_{i}^{*}\left(Y_{j}\right)=\gamma Y_{j}$. Putting all cases together gives the global optimum in lemma $2, Y_{i}^{*}\left(Y_{j}\right)=\min \left\{K_{i}, \gamma Y_{j}\right\}$.

Proposition 1. Follows immediately as the unique fixed point of the best-response correspondence in lemma 2.

Proposition 2. In the fear equilibrium $Y_{1}=K_{1}$ and $Y_{2}=\gamma K_{1}$. Hence, the utility of Agent 2 making a transfer $T$, conditional on the game staying in a fear equilibrium after redistribution, is given by $U_{2}(T)=\ln \left(\gamma\left(K_{1}+T\right)\right)-\gamma\left(K_{1}+T\right) /\left(K_{2}-T\right)$. It is concave in $T$ and $U_{2}^{\prime}(T)=1 /\left(K_{1}+T\right)-\gamma\left(K_{1}+K_{2}\right) /\left(K_{2}-T\right)^{2}$. Note first that $U_{2}^{\prime}(\bar{T})=-(1+\gamma) / \gamma(K 1+K 2)<0$ meaning that the full transfer $\bar{T}$ is never optimal. Next, $U_{2}^{\prime}(0)=1 / K_{1}-\gamma\left(K_{1}+K_{2}\right) / K_{2}^{2} \leqslant 0 \Leftrightarrow k^{2}+k-1 / \gamma \geqslant 0$, which implies that $T^{*}=0 \Leftrightarrow k \geqslant(\sqrt{1+4 / \gamma}-1) / 2$. Otherwise, $T^{*}$ is the solution to the quadratic equation $U_{2}^{\prime}\left(T^{*}\right)=0$ yielding the expression in (A12). Since $\sqrt{\gamma(\gamma+4)}-\gamma$ is increasing in $\gamma, T^{*}$ is decreasing in $\gamma$, when positive. But $\gamma \equiv 1+1 / \sqrt{\tau \theta}$, that is, $T^{*}$ is increasing in $\tau$ and $\theta$, when positive. 


\section{B Description of variables}

Evil eye belief. Presence of the evil eye belief, coded on an ordinal scale from incontrovertibly absent (1) to incontrovertibly present (8). The binary measure was derived by lumping categories (1)-(4) and (5)-(8) into two: absent and present. Original source: Roberts (1976).

Stratification dummy. The original class stratification measure comprises five categories: absence of significant wealth distinctions among freemen (1); wealth distinctions based on the possession and distribution of property, not crystallized into distinct social classes (2); elite stratification, in which an elite class has control over scarce resources, particularly land (3); dual stratification into a hereditary aristocracy and a lower class of ordinary commoners or freemen (4); complex stratification into social classes correlated in large measure with extensive differentiation of occupational statuses (5). Class stratification dummy is equal to 0 for the first category and 1 otherwise. Original source: Murdock (1967).

Specialization. The original technological specialization measure comprises five categories: none (1); pottery only (2); loom weaving only (3); metalwork only (4); smiths, weavers, potters (5). This variable is transformed into an ordinal measure equal to 1 for the first category, 2 for categories (2)-(4), and 3 for the fifth category. It is then multiplied by the class stratification dummy. Original source: Murdock and Provost (1973), author's calculations.

Distance to Babylon. Great circle distance from the location of an SCCS society, as defined by the geographical coordinates in Murdock and White (1969), to the location of Babylon: $\left(32^{\circ} 35^{\prime} \mathrm{N}, 44^{\circ} 45^{\prime} \mathrm{E}\right)$. Computed using the Haversine formula and measured in $1000 \mathrm{~km}$. For the New World (North and South America) this measure is set to zero. Original source: Murdock and White (1969), author's calculations.

Distance to Tenochtitlan. Great circle distance from the location of an SCCS society, as defined by the geographical coordinates in Murdock and White (1969), to the location of Tenochtitlan: $\left(19^{\circ} \mathrm{N}, 99^{\circ} 10^{\prime} \mathrm{W}\right)$. Computed using the Haversine formula and measured in $1000 \mathrm{~km}$. For the Old World (excludes North and South America) this measure is set to zero. Original source: Murdock and White (1969), author's calculations.

Distance to coastline. Great circle distance from an SCCS society, as defined by the geographical coordinates in Murdock and White (1969), to the closest location on the coastline detected using ArcGis software. Computed using the Haversine formula and measured in $1000 \mathrm{~km}$. Original source: Murdock and White (1969), author's calculations using the shapefile for the coastline downloaded at http://www.naturalearthdata.com.

Population density. Mean population density in the territory controlled or exploited by an SCCS society, on the following ordinal scale: less than 1 person per square mile (1); 1-5 persons per square mile (2); $5.1-25$ persons per square mile (3); 26-100 persons per square mile (4); more than 100 persons per square mile. Original source: Murdock and Provost (1973).

Urbanization. Average population of local communities, measured on the following ordinal scale: less than 100 persons (1); 100-199 persons (2); 200-399 persons (3); 400-999 persons (4); more than 1000 persons (5). Original source: Murdock and Provost (1973).

Settlement pattern. A measure of residence fixity, on the ordinal scale: fully nomadic (1); seminomadic (2); semisedentary (3); sedentary but impermanent (4); sedentary and relatively permanent (5). Original source: Murdock and Provost (1973).

Money. Measures the degree of complexity with respect to media of exchange, on the ordinal scale: lack of organized medium of exchange, barter (1); true money is lacking but the society employs domestically usable articles, such as salt, grain, livestock, or ornaments as a medium of exchange (2); the society lacks any form of indigenous money but has long used the currency of an alien people, e.g., that of its colonial rulers (3); indigenous articles of token or conventional value, such as cowrie shells, wampum, or imitation tools, as an elementary form of money (4); indigenous currency in the form of metal coins of standard weight and fineness and/or their equivalent in paper currency (5). Original source: Murdock and Provost (1973).

Local hierarchy. Jurisdictional hierarchy of the local community, on the ordinal scale: theoretical minimum of two levels, e.g., family and band (1); three levels (2); four levels, e.g., nuclear family, extended family, clan-barrios and village (3). Original source: Murdock (1967).

Inheritance of movables/land. Rules for the distribution of inheritance on the categorical scale: absence of individual property rights on movables/land (0); equal or relatively equal distribution (1); transfer to exclusively or predominantly to the one adjudged best qualified (2); ultimogeniture, i.e., transfer to the junior individual (3); primogeniture, i.e., transfer to the senior individual (4). In the analysis the last three categories are merged into a single group standing for exclusive transfer. Original source: Murdock (1967).

Property rights. An indicator of the existence of individual property rights on movables that is set equal to 1 if the above variable for inheritance of movables is greater than 0. Original source: Murdock (1967). 
Jurisdictional hierarchy beyond local community. An ordinal scale indicating the complexity of political organization in terms of the number of distinct jurisdictional levels recognizable in the society: stateless society, with political authority dispersed even at the local level among households and other small component units (1); stateless society composed of politically organized autonomous local communities (2); one administrative level recognized above that of the local community, as in the case of a petty state with a paramount chief ruling over a number of local communities (3); two administrative levels recognized above that of the local community, as in the case of a small state divided into administrative districts (4); three or more administrative levels recognized above that of the local community, as in the case of a large state organized into provinces which are subdivided into districts (5). Original source: Murdock and Provost (1973).

Classical religion. The seven categories in the detailed classification are: traditional religion, deep islamization, superficial islamization, deep christianization, superficial christianization, Buddhism (includes Mahayana, Hinayana, and Vajrayana), and Hinduism. The aggregated version puts deep and superficial islamization in one single group (Islam) and deep and superficial christianization in another one (Christianity). Original source: Korotayev (2004), author's calculations.

Pathogen stress. The pathogens chosen are as follows: leishmanias, trypanosomes, malaria, shistosomes, the filariae, spirochetes, and leprosy. According to Low (1994), these pathogens "meet the criteria of an acute, possibly fatal initial stage of infection, and long-term chronic debilitation or recurrence of acute episodes; further, good worldwide geographic record exists for them." For each pathogen, a three-level code was constructed: absent or not recorded (1), present with no indication of severity (2), present and serious, widespread, or endemic (3). The sum of the scores for all pathogens is used as a measure of total pathogen stress for each society (ranging from 7 to 21). Original source: Low (1994).

Variation in rainfall. Measured as coefficient of variation in mean annual rainfall based on 20 years of rainfall data (from weather stations in close proximity of the SCCS societies), mostly taken from the Global Historical Climatology Network. Original Source: Cashdan (2001).

Theories of illness. Mystical retribution is defined as "acts in violation of some taboo or moral injunction when conceived as causing illness directly rather than through the mediation of an offended or punitive supernatural being." Soul loss refers to "voluntary and more than temporary departure of the patient's soul from his body." Spirit aggression is "direct hostile, arbitrary or punitive action of some malevolent or affronted supernatural being." Sorcery is defined as the "aggressive use of magical techniques by a human being, either independently or with the assistance of a specialized magician or shaman." Witchcraft is the "aggressive action of a member of a special class of human beings believed to be endowed with a special power and propensity for evil." Each phenomenon is coded, based on whether it is used to explain illness, on the following ordinal scale: absence of such as cause (1); minor or relatively unimportant cause (2); an important auxiliary cause (3); predominant cause recognized by the society (4). Original source: Murdock et al. (1978).

Production mode (SCCS). The original variable (subsistence economy: dominant mode) contains the following categories: advanced agriculture, horticulture, simple or shifting cultivation, domestic animals, exchange, fishing, gathering, and hunting. The second and third groups are combined in one, "horticulturalists," and the last 4 groups are joined into "foragers" to get the final four-way classification. Original source: Murdock and White (1969).

Production mode (EA). The final four-way classification is constructed based on the variables measuring percentage dependence of the economy on gathering, hunting, fishing, animal husbandry, and agriculture. The dominant mode of subsistence economy was defined based on the most important contributing component (50 percent and higher). To classify the agricultural societies data on the intensity of agriculture were used comprising the following categories: casual agriculture (1); extensive or shifting agriculture, long fallow, and new fields cleared annually (2); horticulture, vegetal gardens or groves of fruit trees (3); intensive agriculture, using fertilization, crop rotation, or other techniques to shorten or eliminate fallow period (4); intensive irrigated agriculture (5). The first three groups are horticulturalists, while the other two are agriculturalists. Cases, for which the type of agriculture is unknown, were grouped into the category "other." Societies in which several types of subsistence modes contribute equally were classified as "mixed." Original source: Murdock (1967), author's calculations.

Language region/family. A coarse (10 regions) and fine (47 families) classification of indigenous languages spoken by the SCCS societies. Original source: Burton (1999). 


\section{Descriptive statistics}

Table C.1: SCCS by continent and pinpointing date

\begin{tabular}{lcclcc}
\hline Continent & Frequency & Percent & Date & Frequency & Percent \\
\hline Africa & 44 & 23.65 & Before 1800 & 12 & 6.45 \\
Eurasia & 55 & 29.57 & $1800-1849$ & 9 & 4.84 \\
North America & 39 & 20.97 & $1850-1899$ & 44 & 23.65 \\
Oceania & 22 & 11.83 & $1900-1949$ & 90 & 48.39 \\
South America & 26 & 13.98 & $1950-1965$ & 31 & 16.67 \\
\hline Total & 186 & 100 & Total & 186 & 100 \\
\hline
\end{tabular}
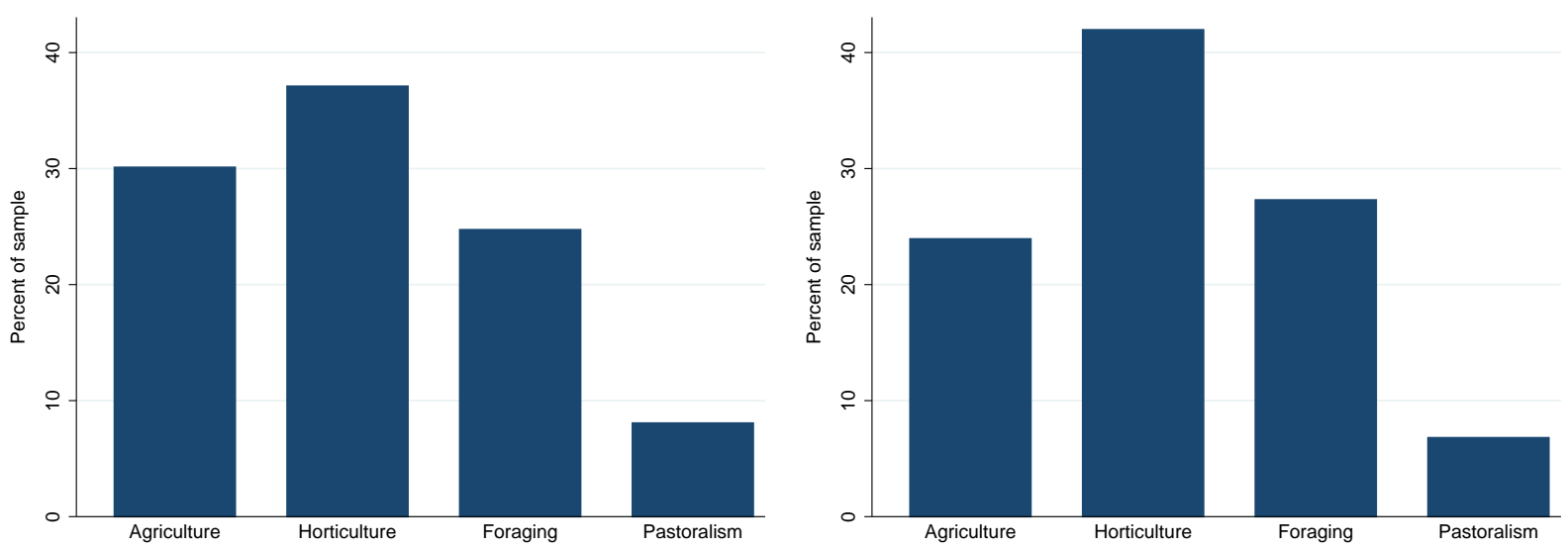

Figure C.1: Production mode: SCCS (left) and EA (right).
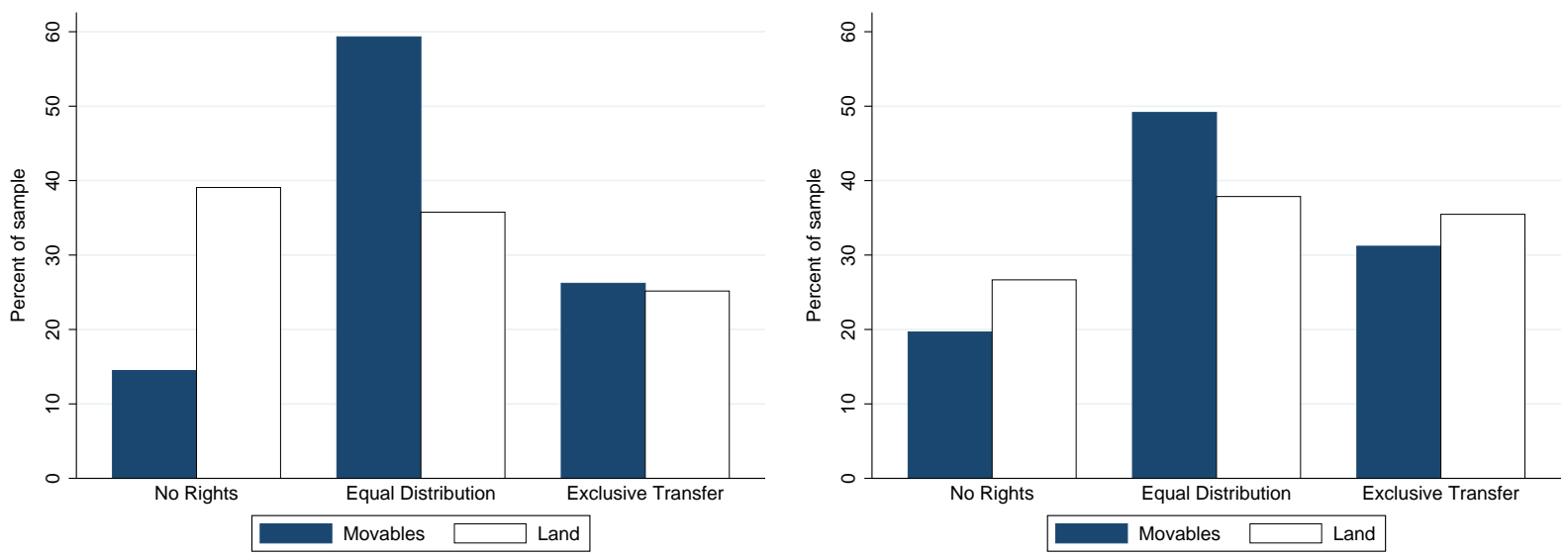

Figure C.2: Inheritance distribution rules: SCCS (left) and EA (right). 


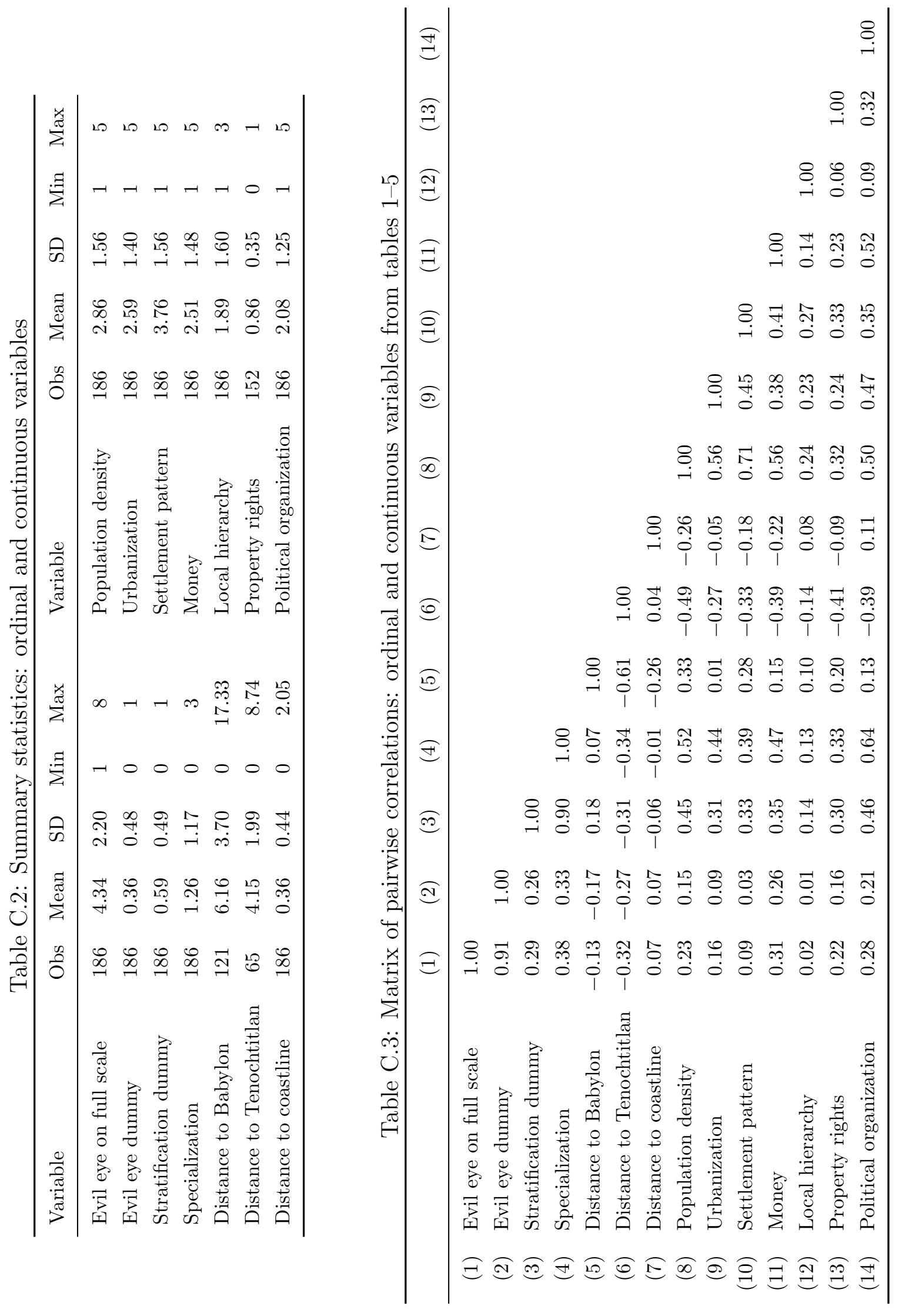




\section{Ordered probit estimates}

Table D.1: Ordered probit estimates

\begin{tabular}{|c|c|c|c|c|c|c|}
\hline & (1) & (2) & (3) & (4) & (5) & (6) \\
\hline Stratification dummy & $\begin{array}{c}0.458^{* *} \\
(0.181)\end{array}$ & $\begin{array}{l}0.446^{* *} \\
(0.183)\end{array}$ & & & & \\
\hline Specialization & & & $\begin{array}{l}0.228^{* * *} \\
(0.082)\end{array}$ & $\begin{array}{l}0.237^{* * *} \\
(0.088)\end{array}$ & & \\
\hline Agriculture & & & & & $\begin{array}{l}0.893^{* * *} \\
(0.261)\end{array}$ & $\begin{array}{c}0.679^{* *} \\
(0.303)\end{array}$ \\
\hline Horticulture & & & & & $\begin{array}{c}0.266 \\
(0.214)\end{array}$ & $\begin{array}{c}0.307 \\
(0.257)\end{array}$ \\
\hline Pastoralism & & & & & $\begin{array}{l}1.491^{* * *} \\
(0.349)\end{array}$ & $\begin{array}{l}1.249^{* * *} \\
(0.370)\end{array}$ \\
\hline Continental dummies & Yes & Yes & Yes & Yes & Yes & Yes \\
\hline Distance controls & Yes & Yes & Yes & Yes & No & Yes \\
\hline Development controls & No & Yes & No & Yes & No & No \\
\hline Observations & 186 & 186 & 186 & 186 & 186 & 186 \\
\hline
\end{tabular}

Notes. a) Dependent variable is the evil eye belief on the $1-8$ scale. b) Robust standard errors in parentheses. c) ${ }^{* * *}$, **, and ${ }^{*}$ denote statistical significance at the 1,5 , and 10 percent level, respectively.

Table D.2: Marginal effects for models (1), (3) and (6) from table D.1

\begin{tabular}{ccccccccc}
\hline Evil eye & 1 & 2 & 3 & 4 & 5 & 6 & 7 & 8 \\
\hline \multirow{2}{*}{$(1)$} & -0.003 & $-0.116^{* *}$ & $-0.058^{* *}$ & 0.017 & $0.013^{*}$ & $0.032^{* *}$ & $0.047^{* *}$ & $0.067^{* *}$ \\
& $(0.003)$ & $(0.049)$ & $(0.025)$ & $(0.011)$ & $(0.008)$ & $(0.016)$ & $(0.022)$ & $(0.027)$ \\
\hline \multirow{2}{*}{$(3)$} & -0.001 & $-0.060^{* * *}$ & $-0.033^{* *}$ & 0.007 & $0.007^{*}$ & $0.017^{* *}$ & $0.026^{* *}$ & $0.037^{* *}$ \\
& $(0.001)$ & $(0.023)$ & $(0.014)$ & $(0.005)$ & $(0.004)$ & $(0.008)$ & $(0.012)$ & $(0.015)$ \\
\hline & -0.002 & $-0.149^{* *}$ & $-0.107^{* *}$ & 0.003 & $0.014^{* *}$ & $0.041^{* *}$ & $0.072^{* *}$ & $0.129^{*}$ \\
& $(0.003)$ & $(0.060)$ & $(0.051)$ & $(0.013)$ & $(0.007)$ & $(0.017)$ & $(0.034)$ & $(0.071)$ \\
$(6)$ & -0.001 & -0.074 & -0.045 & 0.007 & 0.008 & 0.021 & 0.033 & 0.051 \\
& $(0.002)$ & $(0.061)$ & $(0.039)$ & $(0.007)$ & $(0.007)$ & $(0.017)$ & $(0.029)$ & $(0.047)$ \\
& -0.002 & $-0.180^{* * *}$ & $-0.213^{* * *}$ & -0.071 & -0.002 & 0.027 & $0.096^{* * *}$ & $0.344^{* *}$ \\
& $(0.002)$ & $(0.037)$ & $(0.056)$ & $(0.044)$ & $(0.012)$ & $(0.019)$ & $(0.029)$ & $(0.141)$ \\
\hline
\end{tabular}

Notes. a) Reported are the changes in the probability of falling in one of the eight categories given a marginal increase in the corresponding regressor. b) Robust standard errors in parentheses. c) ${ }^{* * *},{ }^{* *}$, and ${ }^{*}$ denote statistical significance at the 1,5 , and 10 percent level, respectively. 


\section{References}

Abu-Rabia, Aref, "The Evil Eye and Cultural Beliefs Among the Bedouin Tribes of the Negev, Middle East," Folklore, December 2005, 116 (3), 241-254.

Alesina, Alberto, Paola Giuliano, and Nathan Nunn, "On the Origins of Gender Roles: Women and the Plough," Quarterly Journal of Economics, May 2013, 128 (2), 469-530.

Anselin, Luc and Sheri Hudak, "Spatial Econometrics in Practice: A Review of Software Options," Regional Science and Urban Economics, September 1992, 22 (3), 509 536.

Ansell, Aaron, "But the Winds Will Turn Against You': An Analysis of Wealth Forms and the Discursive Space of Development in Northeast Brazil," American Ethnologist, February 2009, 36 (1), 96-109.

Ashraf, Quamrul and Oded Galor, "Dynamics and Stagnation in the Malthusian Epoch," American Economic Review, August 2011, 101 (5), 2003-2041.

Baker, Matthew, "A Structural Model of the Transition to Agriculture," Journal of Economic Growth, December 2008, 13 (4), 257-292.

Beck, Jan and Wolfgang Forstmeier, "Superstition and Belief as Inevitable Byproducts of an Adaptive Learning Strategy," Human Nature, Spring 2005, 18 (1), $35-46$.

Benhabib, Jess, Alberto Bisin, and Matthew Jackson, eds, Handbook of Social Economics, Vol. 1, Elsevier, 2011.

Bisin, Alberto and Thierry Verdier, "The Economics of Cultural Transmission and Socialization," in Jess Benhabib, Alberto Bisin, and Matthew Jackson, eds., Handbook of Social Economics, Vol. 1, Elsevier, 2011, chapter 9, pp. 339-416.

Borgerhoff Mulder, Monique, et al., "Intergenerational Wealth Transmission and the Dynamics of Inequality in Small-Scale Societies," Science, October 2009, 326 (682), $682-688$.

Burton, Michael L., "Language and Region Codes for the Standard Cross-Cultural Sample," Cross-Cultural Research, February 1999, 33 (1), 63-83. 
Cancian, Frank, Economics and Prestige in a Maya Community, Stanford, CA: Stanford University Press, 1965.

Cashdan, Elizabeth, "Ethnic Diversity and Its Environmental Determinants: Effects of Climate, Pathogens, and Habitat Diversity," American Anthropologist, December 2001, 103 (4), 968-991.

Chibnik, Michael, "The Evolution of Cultural Rules," Journal of Anthropological Research, Autumn 1981, 37 (3), 256-268.

Conley, Timothy G., "GMM estimation with cross sectional dependence," Journal of Econometrics, September 1999, 92 (1), 1-45.

Davidson, Nestor M., "Property and Relative Status," Michigan Law Review, March 2009, 107 (5), 757-817.

de Vidas, Anath Ariel, "The Symbolic and Ethnic Aspects of Envy among a Teneek Community (Mexico)," Journal of Anthropological Research, Summer 2007, 63 (2), $215-237$.

Diamond, Jared, The World Until Yesterday: What Can We Learn from Traditional Societies?, Viking, 2012.

and Peter Bellwood, "Farmers and Their Languages: The First Expansions," Science, April 2003, 300 (597), 597-603.

Durante, Ruben, "Risk, Cooperation and the Economic Origins of Social Trust: An Empirical Investigation," 2010. Working Paper, Sciences Po, Department of Economics.

Eff, Ellis A., "Does Mr. Galton Still Have a Problem? Autocorrelation in the Standard Cross-Cultural Sample," World Cultures, 2004, 15 (2), 153-170.

_ _ "Weight Matrices for Cultural Proximity: Deriving Weights from a Language Phylogeny," Structure and Dynamics, 2008, 3 (2), 1-15.

Elliott, John H., "The Evil Eye and the Sermon On the Mount," Biblical Interpretation, 1994, 2 (1), 51-84.

Elworthy, Frederick Thomas, The Evil Eye. An Account of This Ancient and Widespread Superstition, London: John Murray, Albemarle Street, 1895. 
Fenske, James, "Does Land Abundance Explain African Institutions?," Economic Journal, December 2013, 123 (573), 13631390.

_ - "Ecology, Trade and States in Pre-Colonial Africa," Journal of the European Economic Association, June 2014, 12 (3), 612640.

Foster, George, "The Anatomy of Envy: A Study in Symbolic Behavior," Current Anthropology, April 1972, 13 (2), 165-202.

Foster, Kevin R. and Hanna Kokko, "The Evolution of Superstitious and Superstitionlike Behaviour," Proceedings of the Royal Society B, 2009, 276, 31-37.

Fudenberg, Drew and David K. Levine, "Superstition and Rational Learning," American Economic Review, June 2006, 96 (3), 630-651.

_ and __ "Self-confirming Equilibrium and the Lucas Critique," Journal of Economic Theory, November 2009, 144 (6), 2354-2371.

Gächter, Othmar, "Evil and Suffering in Hinduism," Anthropos, 1998, 93, 393-403.

Gennaioli, Nicola and Ilia Rainer, "The Modern Impact of Precolonial Centralization in Africa," Journal of Economic Growth, September 2007, 12 (3), 185-234.

Gershman, Boris, "The Two Sides of Envy," February 2014. Working Paper, American University.

"Witchcraft Beliefs and the Erosion of Trust: Evidence from Sub-Saharan Africa," July 2014. Working paper, American University.

Ghosh, Amitav, "The Relations of Envy in an Egyptian Village," Ethnology, July 1983, 22 (3), 211-223.

Gigerenzer, Gerd, Gut Feelings: The Intelligence of the Unconscious, Penguin, 2008.

Giuliano, Paola and Nathan Nunn, "The Transmission of Democracy: From the Village to the Nation-State," American Economic Review Papers and Proceedings, May 2013, 103 (3), 86-92.

Greenberg, James B., Santiago's Sword: Chatino Peasant Religion and Economics, Berkeley and Los Angeles: University of California Press, 1981. 
Grosjean, Pauline, "A History of Violence: The Culture of Honor and Homicide in the U.S. South," Journal of the European Economic Association, 2014, forthcoming.

Harris, Marvin, Cannibals and Kings: The Origins of Cultures, New York: Random House, 1977.

Henrich, Joseph and Robert Boyd, "Division of Labor, Economic Specialization, and the Evolution of Social Stratification," Current Anthropology, August 2008, 49 (4), $715-724$.

Johnson, Allen W. and Timothy Earle, The Evolution of Human Societies: From Foraging Group to Agrarian State, Stanford, CA: Stanford University Press, 1987.

Korotayev, Andrey, World Religions And Social Evolution Of The Old World Oikumene Civilizations: A Cross-cultural Perspective, Edwin Mellen Press, 2004.

Leeson, Peter T., "Ordeals," Journal of Law and Economics, August 2012, 55 (3), 691714.

__ "Human Sacrifice," Review of Behavioral Economics, 2014, 1 (1-2), 137-165.

and Christopher J. Coyne, "Sassywood," Journal of Comparative Economics, November 2012, 40 (4), 608-620.

Lisón-Tolosana, Carmelo, "Some Aspects of Moral Structure in Galician Hamlets," American Anthropologist, June 1973, 75 (3), 823-834.

Low, Bobbi S., "Pathogen Intensity Cross-Culturally," World Cultures, 1994, 8 (1), 2434.

Michalopoulos, Stelios, Alireza Naghavi, and Giovanni Prarolo, "Trade and Geography in the Origins and Spread of Islam," October 2012. NBER Working Paper 18438.

— and Elias Papaioannou, "Pre-Colonial Ethnic Institutions and Contemporary African Development," Econometrica, January 2013, 81 (1), 113-152.

Mui, Vai-Lam, "The Economics of Envy," Journal of Economic Behavior 8 Organization, May 1995, 26 (3), 311-336.

Murdock, George P., Ethnographic Atlas, Pittsburgh, PA: University of Pittsburgh Press, 1967. 
and Caterina Provost, "Measurement of Cultural Complexity," Ethnology, October 1973, $12(4), 379-392$.

and Douglas R. White, "Standard Cross-Cultural Sample," Ethnology, October 1969, 8 (4), 329-369.

, Suzanne F. Wilson, and Violetta Frederick, "World Distribution of Theories of Illness," Ethnology, October 1978, 17 (4), 449-470.

Nunn, Nathan, "Culture and the Historical Process," Economic History of Developing Regions, 2012, 27, S108-S126.

- and Leonard Wantchekon, "The Slave Trade and the Origins of Mistrust in Africa," American Economic Review, December 2011, 101 (7), 3221-3252.

Ortiz de Montellano, Bernard, "Syncretism in Mexican and Mexican-American Folk Medicine," in "Discovering the Americas: 1992 Lecture Series," University of Maryland, College Park, 1989.

Platteau, Jean-Philippe, "Redistributive Pressures in Sub-Saharan Africa: Causes, Consequences, and Coping Strategies," in E. Akyeampong, R. Bates, N. Nunn, and J. Robinson, eds., African Development in Historical Perspective, Cambridge University Press, 2014.

and Robert Peccoud, eds, Culture, Institutions, and Development: New Insights Into an Old Debate, Routledge, 2010.

Reminick, Ronald A., "The Evil Eye Belief Among the Amhara of Ethiopia," Ethnology, July 1974, 13 (3), 279-291.

Richerson, Peter J. and Robert Boyd, Not by Genes Alone: How Culture Transformed Human Evolution, Chicago: University of Chicago Press, 2005.

Roberts, John M., "Belief in the Evil Eye in World Perspective," in Clarence Maloney, ed., The Evil Eye, New York: Columbia University Press, 1976.

Scheibe, Karl E. and Theodore R. Sarbin, "Towards a Theoretical Conceptualisation of Superstition," The British Journal for the Philosophy of Science, August 1965, 16 (62), 143-158.

Schoeck, Helmut, Envy: A Theory of Social Behavior, New York: Harcourt, Brace, and World, 1969. 
_ _ "The Evil Eye: Forms and Dynamics of a Universal Superstition," in Alan Dundes, ed., The Evil Eye: A Folklore Casebook, New York: Garland Publishing, 1981, pp. 192200 .

Seligmann, S., Der Böse Blick und Verwandtes, Berlin: Verlag von Hermann Barsdorf, 1910.

Spooner, Brian, "The Evil Eye in the Middle East," in Mary Douglas, ed., Witchcraft Confessions and Accusations, London: Tavistock Publications, 1970, chapter 15, pp. 311-319.

Stein, Howard F., "Envy and the Evil Eye Among Slovak-Americans: An Essay in the Psychological Ontogeny of Belief and Ritual," Ethos, Spring 1974, 2 (1), 15-46.

Thomsen, Marie-Louise, "The Evil Eye in Mesopotamia," Journal of Near Eastern Studies, January 1992, 51 (1), 19-32.

Wolf, Eric R., "Types of Latin American Peasantry: A Preliminary Discussion," American Anthropologist, June 1955, 57 (3, Part 1), 452-471. 